\title{
Traditional Chinese Medicine is an Alternative Therapeutic Option for Treatment of Pseudomonas aeruginosa Infections
}

\author{
Zheng Pang ${ }^{1,2,3 \star}$ and Qingjun Zhu ${ }^{1,2,3}$ \\ ${ }^{1}$ Innovative Institute of Chinese Medicine and Pharmacy, Shandong University of Traditional Chinese Medicine, Jinan, China, ${ }^{2}$ Key \\ Laboratory of Traditional Chinese Medicine Classical Theory, Ministry of Education, Shandong University of Traditional Chinese \\ Medicine, Jinan, China, ${ }^{3}$ Shandong Provincial Key Laboratory of Traditional Chinese Medicine for Basic Research, Shandong \\ University of Traditional Chinese Medicine, Jinan, China
}

OPEN ACCESS

Edited by:

Cheorl-Ho Kim,

Sungkyunkwan University, South

Korea

Reviewed by: Megan Lloyd

Upstate Medical University, United States

Rambir Singh,

Mizoram University, India

*Correspondence: Zheng Pang

60230021@sdutcm.edu.cn

Specialty section: This article was submitted to

Ethnopharmacology,

a section of the journal

Frontiers in Pharmacology

Received: 06 July 2021 Accepted: 18 August 2021 Published: 27 August 2021

Citation:

Pang $Z$ and Zhu Q (2021) Traditional Chinese Medicine is an Alternative Therapeutic Option for Treatment of Pseudomonas aeruginosa Infections.

Front. Pharmacol. 12:737252.

doi: 10.3389/fphar.2021.737252
Pseudomonas aeruginosa is an opportunistic pathogen causing life-threatening infections in cystic fibrosis patients and immunocompromised individuals, and it is a leading cause of nosocomial infections associated with significant morbidity and mortality. Treatment of $P$. aeruginosa infections is challenging due to the antibiotic resistance to most of the conventional antibiotics. Development of alternative therapeutic options is urgently demanded for the patients who have antibiotic-resistant infections. Traditional Chinese medicine (TCM) has a clinical history of thousands of years for prevention and treatment of infectious diseases in China, taking advantages of improving clinical outcomes, producing less side effects, inhibiting pathogen, and modulating host immunity. Recent research has revealed a variety of natural products derived from TCM showing significant antimicrobial effects on antibiotic-resistant strains of $P$. aeruginosa alone or combined with antibiotics in vitro or in animal models, suggesting that TCM is a promising complementary and alternative therapeutic approach for treatment of chronic $P$. aeruginosa infections. This review summarizes the recent findings attempting to dissect the mechanisms of TCM combating $P$. aeruginosa infections and highlights the molecular targets of TCM on $P$. aeruginosa and host.

Keywords: traditional Chinese medicine, Pseudomonas aeruginosa, quorum sensing, biofilm, bactericidal effects, immunomodulation

\footnotetext{
Abbreviations: ABC, ATP-binding cassette; AHL, N-acyl homoserine lactone; C4-HSL, N-butanoyl-L-homoserine lactone; c-di-GMP, bis- $\left(3^{\prime}-5^{\prime}\right)$-cyclic dimeric guanosine monophosphate; CF, cystic fibrosis; EPS, extracellular polymeric substances; IQS, integrated quorum sensing system; MATE, multidrug and toxic compound extrusion family; MBC, minimum bactericidal concentration; MDR, multidrug-resistant; MFS, major facilitator superfamily; MIC, minimum inhibitory concentration; 3OC12-HSL, N-(3-oxododecanoyl)-L-homoserine lactone; NNIS, national nosocomial infections surveillance; PQS, Pseudomonas quinolone signal; QS, Quorum sensing; RND, resistance-nodulation-division family; SMR, small multidrug resistance; TCM, traditional chinese medicine; WHO, world health organization.
} 


\section{INTRODUCTION}

Pseudomonas aeruginosa is a Gram-negative, rod-shaped, aerobic bacterium that is commonly found in soil and aqueous environments, and is capable of surviving in harsh conditions with minimum nutrition requirement owing to its numerous metabolic pathways and regulatory genes (Moradali et al., 2017). Pseudomonas aeruginosa is also an opportunistic pathogen that can reside on human skin without causing harm in most healthy individuals but causes life-threatening acute infections in immunocompromised individuals and chronic infections in cystic fibrosis (CF) patients (Sadikot et al., 2005). The nosocomial infections caused by $P$. aeruginosa is a major problem in intensive care units with significant mortality and morbidity, which contributes $10-20 \%$ of total nosocomial infection cases (Bodey et al., 1983). According to the data from the National Nosocomial Infections Surveillance (NNIS) System, $P$. aeruginosa is the second most common cause of nosocomial pneumonia (17\%), the third most common cause of urinary tract infection (7\%), and the fourth most common cause of surgical site infection (8\%)(Richards et al., 1999; National Nosocomial Infections Surveillance, 2004). Importantly, this bacterial pathogen is able to counter many of the currently available antibiotics such as aminoglycosides, quinolones and $\beta$-lactams through intrinsic and acquired resistance mechanisms (Pang et al., 2019). The intrinsic mechanisms include low permeability of outer membrane, expression of efflux pumps and production of antibiotic-inactivating enzymes. The acquired resistance mechanisms are achieved by mutational changes or acquisition of resistance genes via horizontal gene transfer, which make the empirical antibiotic treatment become increasingly more difficult and costly (Pang et al., 2019). In particular, the bacterial efflux pumps expelling a broad spectrum of antibiotics from the cell can greatly contribute to multidrug resistance, and they can be classified into five families: resistance-nodulationdivision (RND) family, major facilitator superfamily (MFS), ATP-binding cassette (ABC) superfamily, small multidrug resistance (SMR) family, and multidrug and toxic compound extrusion (MATE) family (Sun J. et al., 2014). Furthermore, the RND efflux pumps play a key role in antibiotic resistance in $P$. aeruginosa, which confer the resistance to a variety of antibiotics including aminoglycosides, quinolones, $\beta$-lactams, macrolides, novobiocin, chloramphenicol, tetracyclines, trimethoprim, sulfonamides and lincomycin (Masuda et al., 2000; Terzi et al., 2014). Although the newly developed antibiotics with novel mechanisms of action have shown increased effectiveness in bacterial killing, $P$. aeruginosa can rapidly evolve resistance and escape from antibiotic targeting through chromosomal mutations, especially in presence of high concentration of antibiotics (Sanz-Garcia et al., 2018; Botelho et al., 2019). Pseudomonas aeruginosa is recognized as one of the six ESKAPE pathogens, including Enterococcus faecium (E), Staphylococcus aureus (S), Klebsiella pneumoniae (K), Acinetobacter baumannii (A), Pseudomonas aeruginosa (P) and Enterobacter Species (E), known for their antimicrobial resistance, and it has been listed by World Health Organization (WHO) as one of the priority bacterial pathogens for research and development of new antibiotics (Tacconelli et al., 2018).

The exploration of complementary and alternative therapeutic strategies against $P$. aeruginosa infections has gained a lot of research attention over the past decade. Many alternative therapeutic approaches including suppression of quorum sensing, inhibition of bacterial lectins, iron chelation, phage therapy, vaccine strategy and nanoparticle application have been assessed and showed antimicrobial activity against multidrug-resistant (MDR) P. aeruginosa in vitro or in animal models (Pang et al., 2019). However, most of them are far from application due to many concerns regarding the cost, side effects and safety. Development of new therapeutic options is still urgently demanded. Traditional Chinese medicine (TCM) has a history over three thousand years, which is a comprehensive health care system comprising of herbal medicine, acupuncture, moxibustion, cupping, massage, and physical exercise (Tang et al., 2008). TCM has a unique therapeutic approach to prevent or treat many diseases such as cancer (Xiang et al., 2019), infectious diseases (Ma et al., 2019), cardiovascular diseases (Hao et al., 2017), Alzheimer's disease (Howes et al., 2017) and diabetes (Tian et al., 2019) by maintaining or restoring the yin-yang balance. For instance, Liao et al. conducted a retrospective cohort study on 111,564 patients with newly diagnosed lung cancer and found that the patients who received TCM treatment had a 32\% lower mortality rate compared to the non-TCM users (Liao et al., 2017). Cardiovascular diseases are the leading cause of death worldwide (Mc Namara et al., 2019). Clinical evidence indicated that the TCM Tiankuijiangya tablet displayed a significant anti-hypertensive effect, which significantly reduced the systolic and diastolic blood pressure in the patients with hypertension by 17.64 and $11.85 \mathrm{~mm} \mathrm{Hg}$, respectively, compared to placebo controls (Hao et al., 2017). Alzheimer's disease is a progressive neurodegenerative disease that is irreversible form of dementia, causing impaired memory and cognitive functions (Cass, 2017). Le Bars et al. demonstrated that $27-37 \%$ of the patients with Alzheimer's disease treated with EGb 761, an extract of Ginkgo biloba L. leaves (Ginkgoaceae), manifested improved cognitive performance and social functioning compared with placebo controls for 6 months to 1 year (Le Bars et al., 1997). More importantly, TCM has a curative effect on infectious diseases with a long history of rich experience, taking advantages of improvement of clinical outcomes, symptom relief, less side effects, pathogen inhibition, and promotion of host immunity during drug-resistant infections (Yu et al., 2017; $\mathrm{Ma}$ et al., 2019). Nowadays, a number of important drugs developed from TCM had significant achievements in public health by controlling many serious infectious diseases. For instance, a Chinese scientist Tu Youyou won the 2015 Nobel Prize for the discovery of artemisinin, a drug extracted from Artemisia annua L. (Compositae) leaves for malaria treatment (Tu, 2016). Furthermore, TCM has been clinically applied for treatment of acute or chronic pulmonary infections in China (Yu et al., 2014; Ma et al., 2019; Ren et al., 2020). During COVID-19 pandemic, greater than $85 \%$ of SARS-CoV-2-infected patients in China had received TCM treatment, and clinical evidence 


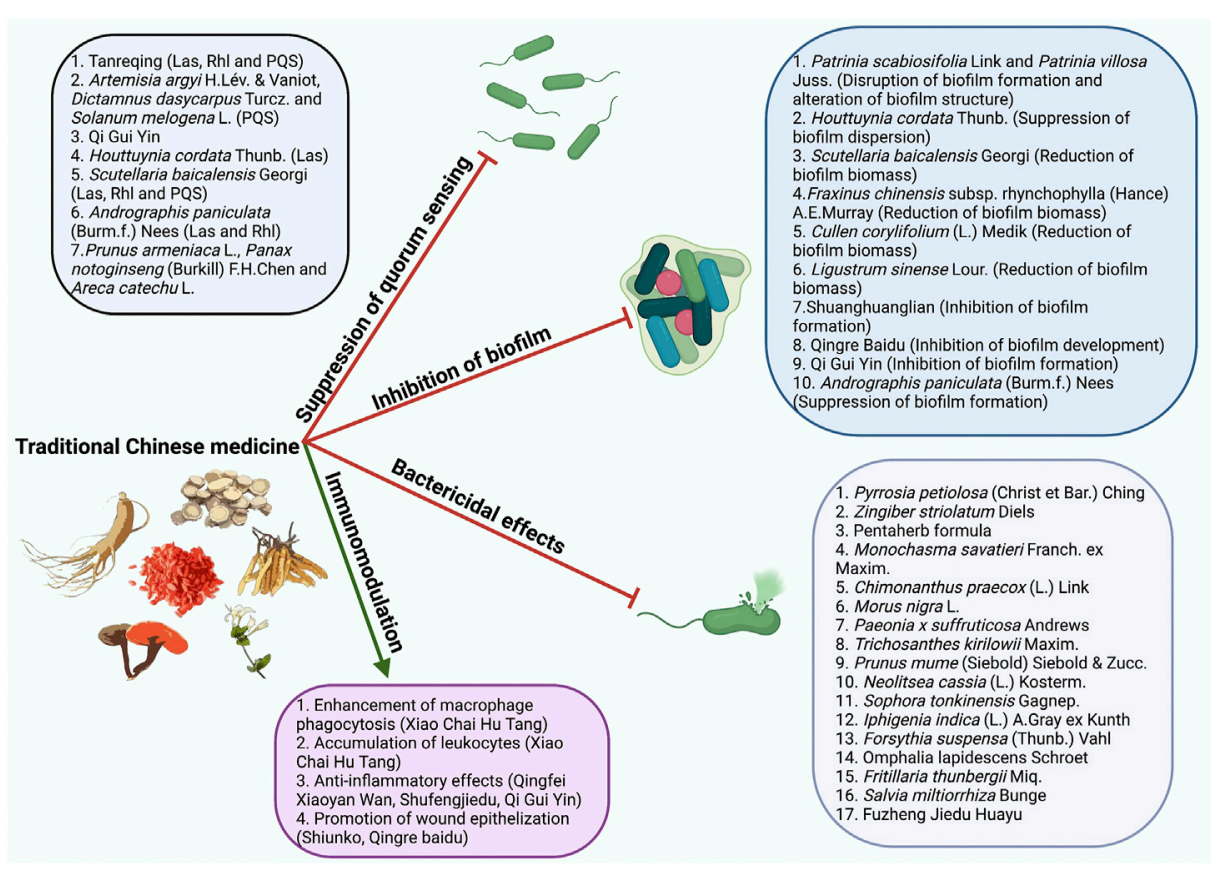

FIGURE 1 | The mechanisms of TCM combating $P$. aeruginosa infections. TCM controls $P$. aeruginosa infections through suppression of QS, inhibition of biofilm, bactericidal effects, and modulation of host immune responses.

indicated that the TCM herbal formulas Qing Fei Pai Du Tang and Lian Hua Qing Wen capsule could significantly alleviate the symptoms, reduce the inflammation, and promote the recovery of COVID-19 patients, and both TCM formulas displayed an effective rate over $90 \%$ for COVID-19 treatment (Yang Y. et al., 2020; Du et al., 2020; Li et al., 2020; Ren et al., 2020; Wu et al., 2020).

TCM has been reported to be capable of effectively controlling $P$. aeruginosa infections through suppression of quorum sensing (QS)(Wei et al., 2020), inhibition of biofilm (Fu et al., 2017), bactericidal effects (Liu et al., 2013), and modulation of host immunity (Hou et al., 2016) (Figure 1). The present review aimed to summarize and discuss the recent findings on the mechanisms of TCM underlying the prevention and treatment of $P$. aeruginosa infections. The scientific names and corresponding common names of the TCM presented in this review were summarized in Table 1.

\section{Suppression of Quorum Sensing}

QS is a bacterial cell-cell communication mechanism that regulates bacterial gene expression in a population densitydependent manner (Miller and Bassler, 2001). Pseudomonas aeruginosa utilizes four QS systems, LasI/LasR, RhlI/RhlR, $\mathrm{PQS} / \mathrm{MvfR}$ and IQS, to activate expression of many virulence factors, including pyocyanin, pyoverdine, elastases, alkaline protease, lectins, rhamnolipids and exotoxin A, which promote bacterial invasion and impair host immune response (Whiteley et al., 1999; Rutherford and Bassler, 2012; Lee et al., 2013). Specifically, $P$. aeruginosa pyocyanin is redox-active phenazine that is not only involved in maintaining bacterial fitness and facilitating biofilm formation but also interferes host cellular functions, such as electron transport, cellular respiration, ciliary function and inflammatory response (Rada and Leto, 2013; Jayaseelan et al., 2014). Pyoverdine is the major siderophore of $P$. aeruginosa that obtains extracellular iron from environment and host proteins, important for bacterial growth and virulence (Meyer, 2000). The elastases produced by $P$. aeruginosa are capable of damaging host tissues and degrading plasma proteins, including immunoglobulins, coagulation factors and complement proteins (Wretlind and Pavlovskis, 1983). Alkaline protease not only damages host tissues but also facilitates bacterial immune evasion through proteolytic cleavage of monomeric flagellin, thus impairing the Toll-like receptor five signaling (Bardoel et al., 2012). Lectins are adhesion molecules located on bacterial outer membrane, which recognize and bind to host glycoconjugates, allowing the attachment of bacteria to host cell surface (Imberty and Varrot, 2008). Rhamnolipids are a class of glycolipid biosurfactants mainly produced by $P$. aeruginosa, and they have multiple functions involved in modification of surface properties, modulation of bacterial swarming motility, disruption of biofilm and alteration of epithelial tight junction (Zulianello et al., 2006; Alhede et al., 2014). Exotoxin A is a highly toxic virulence factor of $P$. aeruginosa that is secreted into the extracellular environment and inhibits host protein synthesis by catalyzing ADP-ribosylation of elongation factor 2 (Michalska and Wolf, 2015).

The LasI/LasR and RhlI/RhlR are two canonical LuxI/LuxR QS circuits in $P$. aeruginosa, which catalyze the synthesis of $\mathrm{N}$-acyl homoserine lactone (AHL) autoinducers, N-(3-oxododecanoyl)- 
TABLE 1 | Summaries of the scientific and common names of TCM ingredients.

\section{TCM scientific names}

Lonicera japonica Thunb.

Scutellaria baicalensis Georgi

Forsythia suspensa (Thunb.) Vahl

Pulvis Fellis Ursi

Cornu Saigae Tataricae

Artemisia argyi H.Lév. \& Vaniot

Dictamnus dasycarpus Turcz.

Solanum melongena L.

Astragalus mongholicus Bunge

Angelica sinensis (Oliv.) Diels

Artemisia annua L.

Reynoutria japonica Houtt.

Houttuynia cordata Thunb.

Andrographis paniculata (Burm.f.) Nees

Prunus armeniaca L.

Panax notoginseng (Burkill) F.H.Chen

Areca catechu L.

Patrinia scabiosifolia Link

Patrinia villosa Juss.

Fraxinus chinensis subsp. rhynchophylla (Hance) A.E.Murray

Cullen corylifolium (L.) Medik

Viola mandshurica W.Becker

Paeonia lactiflora pall.

Salvia miltiorrhiza Bunge

Gleditsia sinensis Lam.

Glycyrrhiza glabra L.

Pyrrosia petiolosa (Christ et Bar.) Ching

Zingiber striolatum Diels

Mentha canadensis L.

Paeonia $\times$ suffruticosa Andrews

Atractylodes lancea (Thunb.) DC.

Phellodendron chinense C.K.Schneid

Monochasma savatieri Franch. ex Maxim.

Chimonanthus praecox (L.) Link

Morus nigra L.

Trichosanthes kirilowii Maxim.

Prunus mume (Siebold) Siebold \& Zucc.

Neolitsea cassia (L.) Kosterm

Sophora tonkinensis Gagnep.

Iphigenia indica (L.) A.Gray ex Kunth

Omphalia lapidescens Schroet

Fritillaria thunbergii Miq.

Echinops latifolius Tausch

Panax quinquefolius L.

Coix lacryma-jobi var. ma-yuen (Rom.Caill.) Stapf

Ephedra sinica Stapf

Gypsum Fibrosum

Pheretima

Arctium lappa L.

Descurainia sophia (L.) Webb ex Prantl

Bovis Calculus Artifactus

Pinellia ternata (Thunb.) Makino

Ziziphus jujuba Mill.

Bupleurum chinense DC.

Panax ginseng C.A.Mey.

Glycyrrhiza glabra L.

Zingiber officinale Roscoe

\section{TCM common names}

Japanese honeysuckle, golden-and-silver honeysuckle

Baikal skullcap, Chinese skullcap

Weeping forsythia, golden-bell

Bear bile

Antelope's Horn

Silvery wormwood or Chinese mugwort

Dittany bark

Eggplant

Mongolian milkvetch

Chinese angelica, Dang Gui

Sweet wormwood, sweet annie, annual wormwood

Japanese knotweed

Fish mint, fish leaf, rainbow plant, chameleon plant, heart leaf, fish wort, Chinese lizard tail

Creat, green chiretta, king of bitters

Apricot

Chinese ginseng, notoginseng

Betelnut palm

Patrinia, eastern valerian

Patrinia

Chinese ash

Babchi, Bakuchi

Manchurian Violet, sumire

Chinese peony

Red sage, Chinese sage, Tanshen, Danshen

Chinese honey locust

Liquorice, licorice

Tongue fern, Japanese felt fern

Yang-he

American wild mint

Moutan peony

Southern tsangshu

Chinese corktree

Not applicable

Wintersweet

Black mulberry

Chinese snake gourd

Chinese plum

Grey bollywood

Vietnamese sophora

Not applicable

Omphalia, Leiwan, Thunder Ball

Zhejiang fritillary

Not applicable

American ginseng

Not applicable

Chinese ephedra

Gypsum

Earthworm

Greater burdock

Flixweed

Artificial ox bezoar

Crow-dipper

Chinese jujube

Chinese thoroughwax

Asian ginseng, Chinese ginseng, Korean ginseng

Liquorice, licorice

Garden ginger
L-homoserine lactone (3O-C12-HSL) and N-butanoyl-Lhomoserine lactone (C4-HSL), respectively (Waters and Bassler, 2005; Lee and Zhang, 2015; Moradali et al., 2017). Subsequently, the signal molecules $3 \mathrm{O}-\mathrm{C} 12-\mathrm{HSL}$ and C4-HSL bind to their respective cognate transcriptional regulators LasR and RhlR, and activate expression of QS-controlled virulence genes (Lee and Zhang, 2015). The Las system regulates the expression of virulence factors, including exotoxin A, LasA 


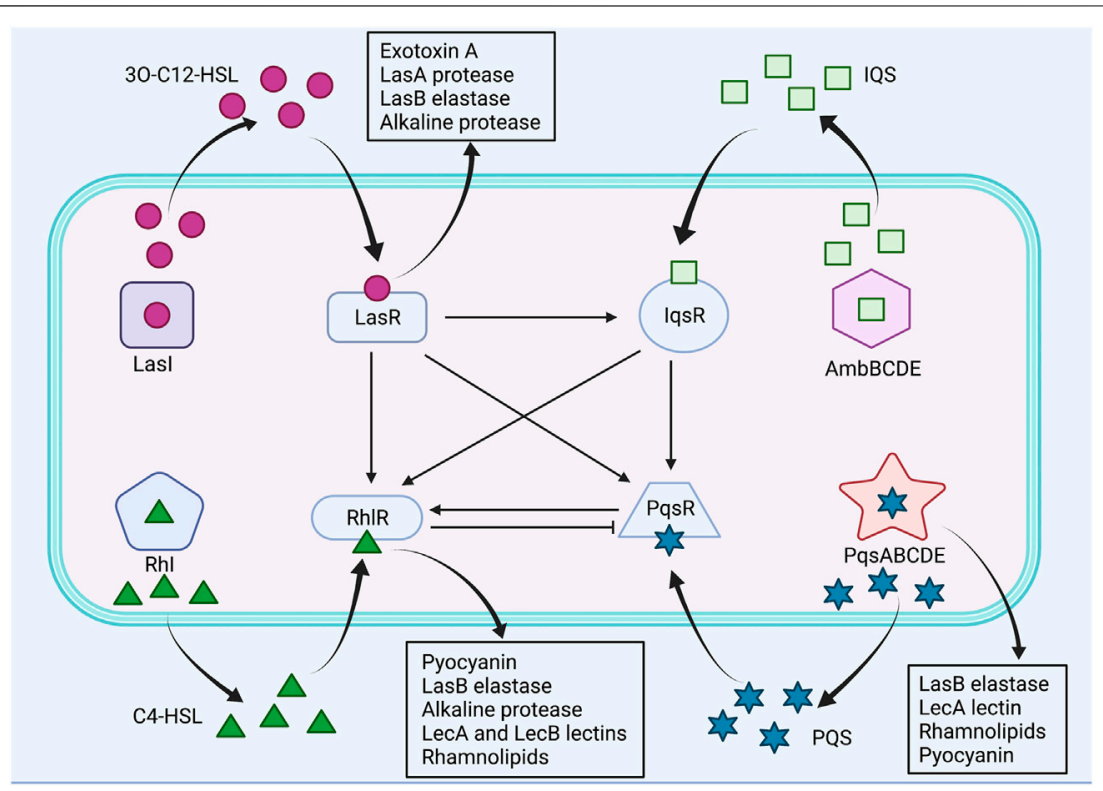

FIGURE 2|The QS systems of $P$. aeruginosa and their interactions. Pseudomonas aeruginosa utilizes four QS systems, including Lasl/LasR, Rhll/RhIR, PQS/MvfR and IQS systems. Las system positively regulates Rhl, PQS and IQS systems. Rhl system negatively regulates PQS system, whereas PQS system positively regulates Rhl system. IQS system positively regulates Rhl and PQS systems. Positive control is represented by arrows, and negative control is represented by blunted arrows.

TABLE 2 | Summaries of the TCM for suppression of $P$. aeruginosa QS.

TCM

Tanreqing

Dry distillation oil from the leaf of Artemisia argyi H.Lév. \& Vaniot., the PQS root bark of Dictamnus dasycarpus Turcz. and the root of Solanum melongena L.

Qi Gui Yin

Sodium houttuyfonate from Houttuynia cordata Thunb. Baicalin from Scutellaria baicalensis Georgi

Andrographolide compounds from Andrographis paniculata (Burm.f.) Las and Rhl Nees

Seed of Prunus armeniaca L., flower and root of Panax notoginseng Not specified (Burkill) F.H.Chen, and seed of Areca catechu L.

\section{Suppression}

of QS

as, $\mathrm{Rhl}$ and $\mathrm{PQS}$

Las

Las, Rhl and PQS
Mechanisms

Repression of QS two-component systems GacS/GacA and PprA/PprB

Interruption of the binding of PqsR to pqsA Wei et al. (2020) promoter

Downregulation of expression of PhzA, PhzB, Ding et al. (2021a) PhzM and MetQ1

Inhibition of Lasl and LasR expression Wu et al. (2014)

Downregulation of transcription of lasl, lasR, rhll, rhIR, pqsR and pqsA

Inhibition of lasl, lasR, rhll and rhIR expression

Impairment of $P$. aeruginosa swarming motility
Luo et al. (2017)

Banerjee et al. (2017); Tan Lim et al. (2021) Koh and Tham, (2011) protease, LasB elastase and alkaline protease, whereas the $\mathrm{Rhl}$ system regulates the expression of the pyocyanin, LasB elastase, alkaline protease, LecA and LecB lectins, and rhamnolipids (Pearson et al., 1997; Glessner et al., 1999; Winzer et al., 2000; Kariminik et al., 2017). Moreover, Las system has shown to positively regulate Rhl system (Lee and Zhang, 2015). By contrast, the third QS signal, Pseudomonas quinolone signal (PQS), structurally identified as 2-heptyl-3-hydroxy-4quinolone, is synthesized through multiple operons, including pqsABCDE, phnAB and pqsH, and it binds to the receptor PqsR, also known as MvfR, to activate production of PQS itself and virulence factors, such as LasB elastase, rhamnolipids, lecA lectin and pyocyanin (Lee and Zhang, 2015; Lin et al., 2018). Furthermore, the PQS synthesis was found to be negatively regulated by $\mathrm{Rhl}$ system and positively regulated by Las system, whereas $\mathrm{PQS}$ positively regulated Rhl system (McKnight et al., 2000; Wade et al., 2005). The fourth QS signal, integrated quorum sensing system (IQS), structurally characterized to be 2-(2-hydroxyphenyl)-thiazole-4carbaldehyde, is synthesized via a gene cluster ambBCDE, and it is responsible for integrating bacterial stress response with the QS network (Lee and Zhang, 2015). In addition, IQS was identified to be tightly controlled by Las system under rich culture conditions but is activated by phosphate limitation 
stress, subsequently upregulating Rhl and PQS systems (Lee et al., 2013). The P. aeruginosa QS systems were illustrated in Figure 2.

Many Chinese herbal medicines have been reported to possess anti-QS activities (Table 2) (Koh and Tham, 2011). Tanreqing injection has been widely used as an herbal formula for the treatment of viral pneumonia in China, which consists of the extracts from the flower bud of Lonicera japonica Thunb. (Caprifoliaceae; Lonicerae Japonicae Flos), the root of Scutellaria baicalensis Georgi (Lamiaceae; Scutellariae Radix), the fruit of Forsythia suspensa (Thunb.) Vahl (Oleaceae; Forsythiae Fructus), Pulvis Fellis Ursi (Bear bile), and Cornu Saigae Tataricae (Antelope's Horn) (Liu et al., 2020). Moreover, the side effects of Tanreqing injection include anaphylaxis, drug eruption, nausea, vomiting and arrhythmia (Liu et al., 2020). A recent study by Yang et al. showed that the five components of Tanreqing played the major role in inhibiting the three $P$. aeruginosa systems, Las, Rhl and PQS, through repression of the upstream two-component systems GacS/GacA and PprA/ PprB, leading to decreased expression of QS-regulated virulence genes in $P$. aeruginosa. Furthermore, the authors demonstrated a Caenorhabditis elegans- $P$. aeruginosa slow-killing assay and found that the survival rate of the $C$. elegans fed with Tanreqing-treated $P$. aeruginos $a$ was significantly increased by $30 \%$ compared to those fed with untreated $P$. aeruginosa, suggesting that Tanreqing reduced the virulence of $P$. aeruginosa and protected C. elegans from killing (Yang W. et al., 2020). However, the original concentration of Tanreqing injection was not provided in this study. Wei et al. introduced a dry distillation oil prepared from a mixture of the leaf of Artemisia argyi H.Lév. \& Vaniot (Compositae; Artemisiae argyi Folium), the root bark of Dictamnus dasycarpus Turcz. (Rutaceae, Dictamni radicis cortex) and the root of Solanum melongena L. (Solanaceae) with a mixing ratio of $1: 1: 2$ (1 part of Artemisiae argyi Folium, 1 part of Dictamni radicis cortex, and 2 parts of the root of Solanum melongena L.) by heating in a flask with condenser tube at $350^{\circ} \mathrm{C}$, and they found the oil was able to inhibit $P$. aeruginosa $\mathrm{PQS}$ system by interrupting the binding of the PQS receptor PqsR to its corresponding promoter pqsA (Wei et al., 2020). No side effects of the three TCM herbs have been reported. Qi Gui Yin is a mixture of Chinese herbal medicines, comprising of the root of Astragalus mongholicus Bunge (Leguminosae, Astragali Radix), the root of Angelica sinensis (Oliv.) Diels (Apiaceae, Angelicae sinensis Radix), the flower bud of L. japonica Thunb. (Caprifoliaceae; Lonicerae Japonicae Flos), Artemisia annua L. (Compositae), and the root and rhizome of Reynoutria japonica Houtt. (Polygonaceae; Polygoni Cuspidati Rhizoma et Radix) at a ratio of 12:3: $3: 2: 2$, and it has been found to effectively eliminate antibiotic-resistant $P$. aeruginosa strains (Kong et al., 2015; Ding et al., 2021a). The safety of Qi Gui Yin decoction has been tested on rats, and no toxic and side effects were observed at a dose of $14.3 \mathrm{~g}$ for every $\mathrm{kg}$ of body weight for 13 weeks (Ding et al., 2021b). Ding et al. analyzed the protein expression profiles of the P. aeruginosa strains treated or not treated with Qi Gui Yin decoction, and found the QS-associated proteins, PhzA, PhzB, PhzM and MetQ1, were downregulated in Qi Gui Yin-treated strains. Further study demonstrated that the serum from Qi Gui
Yin-treated rats could effectively reduce the resistance of $P$. aeruginosa to imipenem (Ding et al., 2021a). However, the mechanisms underlying the Qi Gui Yin-mediated QS inhibition were not specified in this study, and the metabolites in the serum of Qi Gui Yin-treated rats need to be further characterized. Sodium houttuyfonate is a bioactive compound derived from Houttuynia cordata Thunb. (Saururaceae), a wellknown TCM botanical drug in East Asia. A study by Wu et al. reported that Sodium houttuyfonate was able to inhibit the expression of $P$. aeruginosa LasI and LasR, leading to impaired production of QS-regulated virulence factors, including pyocyanin and LasA (Wu et al., 2014). It is noteworthy that H. cordata Thunb. may cause allergic reactions in some people (Shingnaisui et al., 2018). Baicalin is an active compound purified from S. baicalensis Georgi, a famous TCM known for its antioxidant, anti-inflammatory and anticoagulant properties (Kong et al., 2014; Lee et al., 2015). Furthermore, baicalin has been found to inhibit the Las, Rhl and PQS systems of $P$. aeruginosa by downregulating the expression of QS regulatory genes, including lasI, lasR, rhlI, rhlR, pqsR and pqsA (Luo et al., 2017). However, S. baicalensis Georgi may cause stomach discomfort, diarrhoea and drug eruption in individual patients (Zhao et al., 2019). Andrographis paniculata (Burm.f.) Nees (Acanthaceae) is a medicinal plant widely used in many Asian countries, including China, India and Thailand, and it has been extensively applied in treatment of upper respiratory infections (Jiang et al., 2021), and it has no obvious toxic and side effects on human and animals (Jayakumar et al., 2013). Zhang et al. identified that the andrographolide compounds, andrographolide, 14-deoxyandrographolide, 14-deoxy-12hydroxyandrographolide and neoandrographolide, from $A$. paniculata (Burm.f.) Nees suppressed the gene expression of LasR in the clinical isolates of $P$. aeruginosa PA22 and PA247 (Tan Lim et al., 2021). Additionally, Banerjee et al. indicated that the chloroform extract of $A$. paniculata (Burm.f.) Nees effectively decreased the expression of lasI, lasR, rhlI and rhlR by 61, 75, 41, and $44 \%$ in $P$. aeruginosa PAO1, respectively (Banerjee et al., 2017). QS has been found to regulate bacterial swarming motility, which is a flagella-driven movement of bacterial cells on a moist surface (Daniels et al., 2004). Koh et al. used swarming motility as an indicator of QS activity to screen the QS inhibitory effects of TCM plants, and they found that acetone and water (1:1 ratio) extracts from the seed of Prunus armeniaca L. (Rosaceae), the flower and root of Panax notoginseng (Burkill) F.H.Chen (Araliaceae), and the seed of Areca catechu L. (Arecaceae) impaired the swarming motility of $P$. aeruginosa PAO1 (Koh and Tham, 2011). However, the inhibitory mechanisms of these TCM botanical drugs were not addressed. Additionally, the side effects of $P$. armeniaca L. remain unknown, whereas $P$. notoginseng (Burkill) F.H.Chen has shown toxic effects on liver and kidney (Wang et al., 2016), and A. catechu L. may cause diarrhea, stomach discomfort and nausea (Samappito et al., 2012).

\section{Inhibition of Biofilm}

A biofilm is an aggregate of microorganisms in which cells adhere to each other on a static surface, and the adherent cells are 


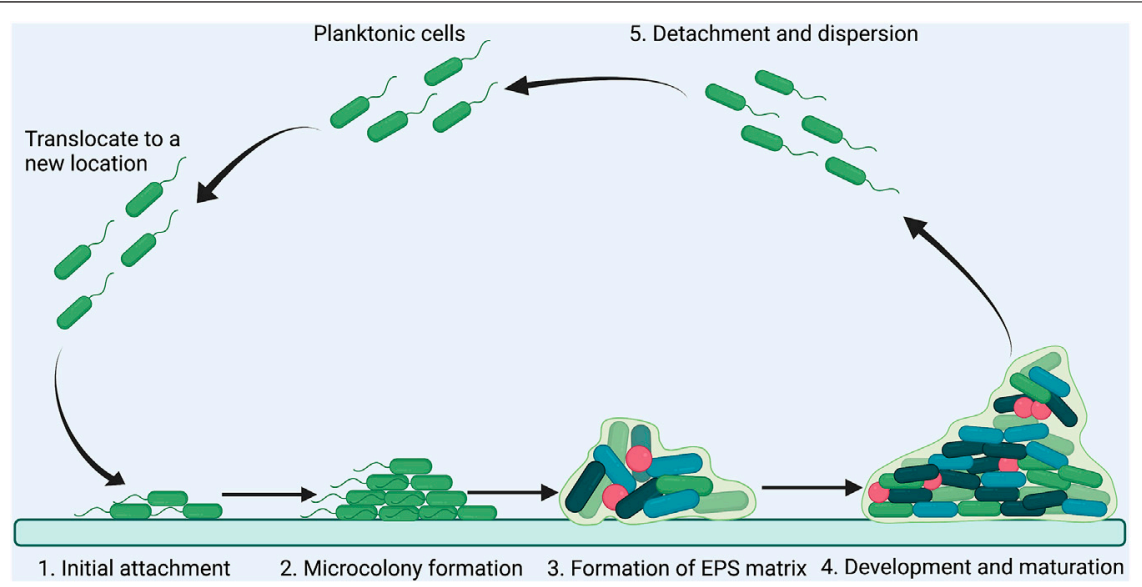

FIGURE 3|Schematic illustration of the steps involved in $P$. aeruginosa biofilm formation. The formation of $P$. aeruginosa biofilm has five steps: (A) initial attachment of planktonic bacteria to a surface; (B) microcolony formation; (C) formation of EPS matrix; (D) development and maturation; (E) detachment and dispersion.

embedded within a self-produced matrix of extracellular polymeric substances (EPS), consisting of polysaccharides, proteins, DNA and lipids (Donlan, 2002). Generally, biofilm formation can be divided into five steps: 1) initial attachment of planktonic bacteria to a surface; 2) microcolony formation; 3 ) formation of matrix by producing EPS; 4) maturation of biofilm into a three-dimensional structure; 5) detachment and dispersion of the biofilm (Figure 3)(Jamal et al., 2018; O’Toole et al., 2000). Bacteria in biofilm are more resistant to antimicrobial agents than planktonic cells because of the poor antibiotic penetration, reduced metabolic and growth rates, induction of adaptive stress responses, and formation of persister cells in biofilm microenvironment (Stewart, 2002; Hoiby et al., 2010). Importantly, approximate $80 \%$ of chronic infections are associated with biofilm formation (Jamal et al., 2018). Disruption of biofilm is critical for controlling persistent bacterial infections.

Pseudomonas aeruginosa is a major cause of chronic respiratory infections in CF patients, leading to declined pulmonary function and ultimate mortality (Lyczak et al., 2002). Formation of $P$. aeruginosa biofilm is regulated by QS systems, two-component regulatory systems, exopolysaccharides and bis- $\left(3^{\prime}-5^{\prime}\right)$-cyclic dimeric guanosine monophosphate (c-diGMP)(Rasamiravaka et al., 2015). Two-component regulatory systems consist of a sensor kinase and a response regulator, which are essential for signaling transduction in bacteria in response to environment stimuli (Mikkelsen et al., 2011). The twocomponent regulatory systems GacS/GacA and RetS/LadS are responsible for regulation of $P$. aeruginosa biofilm formation (Rasamiravaka et al., 2015). The exopolysaccharides produced by $P$. aeruginosa include alginate, $\mathrm{Pel}$ and Psl, which contribute to biofilm development and stabilize biofilm architecture (Ghafoor et al., 2011). The c-di-GMP is a nucleotide second messenger that regulates plentiful cellular processes in bacteria, and high levels of c-di-GMP repress bacterial motility and induce production of exopolysaccharides, which promote $P$. aeruginosa biofilm formation (Ha and O'Toole, 2015).
TCM botanical drugs have manifested inhibitory effects on $P$. aeruginosa biofilm (Table 3)(Fu et al., 2017; Wang T. et al., 2019; Xu Z. et al., 2019). Herba patriniae, also known as Bai Jiang Cao, is a TCM for heat-clearing and detoxication, consisting of two species of Caprifoliaceae family, Patrinia scabiosifolia Link (Caprifoliaceae) and Patrinia villosa Juss. (Caprifoliaceae) (Gong et al., 2021). Fu et al. reported that the water extract of Herba patriniae was able to disrupt the biofilm formation and alter the biofilm structure of $P$. aeruginosa PAO1 through inhibition of exopolysaccharide production and biofilmassociated genes including $\operatorname{alg} U, p s l M, p e l A$, algA, and $b d l A$ (Fu et al., 2017). However, the authors did not specify the species of Herba patriniae in this study. Additionally, the mild side effects including temporary leukopenia, dizziness and nausea could be found in the patients treated with inappropriate dose of Herba Patriniae (Gong et al., 2021). As mentioned earlier, sodium houttuyfonate from $H$. cordata Thunb. could inhibit $P$. aeruginosa QS systems (Wu et al., 2014). A study by Wang et al. identified that sodium houttuyfonate was able to penetrate $P$. aeruginosa biofilm and suppress biofilm dispersion by inhibiting the expression of the key biofilm regulator BdlA (Wang T. et al., 2019). Moreover, Wu et al. set up a rat model of $P$. aeruginosa biofilm infections in airway, and they found that sodium houttuyfonate destructed biofilm formation and the sodium houttuyfonate-treated rat displayed reduced symptoms and pulmonary inflammation (Wu et al., 2016). Zeng et al. examined the effects of several TCM chemical compounds on $P$. aeruginosa biofilm and found that the Baicalin and Baicalein from S. baicalensis Georgi, the Esculetin and Esculin from Fraxinus chinensis subsp. rhynchophylla (Hance) A.E.Murray (Oleaceae), and the Psoralen from Cullen corylifolium (L.) Medik (Leguminosae) could significantly reduce the mass of $P$. aeruginosa biofilm (Zeng et al., 2008). The mechanisms involved in the reduction of biofilm biomass by the three active compounds need to be further explored. Furthermore, the side effects of F. chinensis subsp. rhynchophylla (Hance) A.E.Murray and C. corylifolium (L.) Medik have not yet been clinically 
TABLE 3 | Summaries of the TCM for inhibition of $P$. aeruginosa biofilm.

\begin{tabular}{|c|c|c|c|}
\hline TCM & Effects on biofilm & Mechanisms & References \\
\hline $\begin{array}{l}\text { Patrinia scabiosifolia Link and Patrinia villosa } \\
\text { Juss. }\end{array}$ & $\begin{array}{l}\text { Disruption of biofilm formation and } \\
\text { alteration of biofilm structure }\end{array}$ & $\begin{array}{l}\text { Inhibition of exopolysaccharide production, and the } \\
\text { expression of } a / g U, p s / M, p e l A, \operatorname{alg} A \text {, and } b d l A\end{array}$ & Fu et al. (2017) \\
\hline $\begin{array}{l}\text { Sodium houttuyfonate from Houttuynia cordata } \\
\text { Thunb. }\end{array}$ & $\begin{array}{l}\text { Suppression of biofilm formation } \\
\text { and dispersion }\end{array}$ & Inhibition of BdlA expression & $\begin{array}{l}\text { Wu et al. (2016); Wang } \\
\text { et al. (2019b) }\end{array}$ \\
\hline $\begin{array}{l}\text { Baicalin and Baicalein from Scutellaria } \\
\text { baicalensis Georgi }\end{array}$ & Reduction of biofilm biomass & Not specified & Zeng et al. (2008) \\
\hline $\begin{array}{l}\text { Esculetin and Esculin from Fraxinus chinensis } \\
\text { subsp. rhynchophylla (Hance) A.E.Murray }\end{array}$ & Reduction of biofilm biomass & Not specified & Zeng et al. (2008) \\
\hline Psoralen from Psoralea corylifolia L. & Reduction of biofilm biomass & Not specified & Zeng et al. (2008) \\
\hline Ligustrum sinense Lour. & Reduction of biofilm biomass & Not specified & Yang et al. (2013) \\
\hline Lonicerin from Shuanghuanglian & Inhibition of biofilm formation & Inhibition of alginate secretion by sequestering AlgE & Xu H. et al. (2019) \\
\hline Qingre Baidu mixture & Inhibition of biofilm development & Downregulation of $\mathrm{Al} 2$ & Shan et al. (2019) \\
\hline Qi Gui Yin & Inhibition of biofilm formation & Downregulate of expression of $\operatorname{ArcA}$ and $I s c U$ & Ding et al. (2021a) \\
\hline $\begin{array}{l}\text { Andrographolide compounds from } \\
\text { Andrographis paniculata (Burm.f.) Nees }\end{array}$ & Suppression of biofilm formation & Not specified & $\begin{array}{l}\text { Banerjee et al. (2017); Tan } \\
\text { Lim et al. (2021) }\end{array}$ \\
\hline
\end{tabular}

reported. Ligustrum sinense Lour. (Oleaceae) is an evergreen shrub used in TCM for their anti-oxidative, anti-tumor, and diuretic properties (Ouyang et al., 2003; Yang et al., 2013), and the side effects of this TCM are not clear. A previous study revealed that the water-soluble extract of $L$. sinense Lour. $(4 \mathrm{mg} / \mathrm{ml})$ could strongly decrease the biomass of $P$. aeruginosa biofilm, and $1.35 \mathrm{mg} / \mathrm{ml}$ of this extract displayed a synergistic inhibitory effect with gentamycin sulphate $(2 \mathrm{mg} / \mathrm{ml})$ on the growth of $P$. aeruginosa PAO1 (Yang et al., 2013). Shuanghuanglian is an antiviral and antibacterial TCM formula comprised of the flower bud of L. japonica Thunb., the root of S. baicalensis Georgi, and the fruit of F. suspensa (Thunb.) Vahl (Yan et al., 2013), and Shuanghuanglian injection has been reported to induce skin allergic reactions (Wang et al., 2010). Xu et al. demonstrated that the Lonicerin, a flavonoid from the Shuanghuanglian component L. japonica Thunb., inhibited the alginate secretion of $P$. aeruginosa by sequestering alginate secretion protein AlgE, thus leading to reduced $P$. aeruginosa biofilm formation (Xu $\mathrm{Z}$. et al., 2019). Qingre Baidu mixture is a TCM formula composed of A. sinensis (Oliv.) Diels, Viola mandshurica W.Becker (Violaceae), the flower bud of L. japonica Thunb., Paeonia lactiflora pall. (Paeoniaceae), Salvia miltiorrhiza Bunge (Lamiaceae; Salviae miltiorrhizae radix et rhizome), F. suspensa (Thunb.) Vahl, the root of A. mongholicus Bunge, Gleditsia sinensis Lam. (Leguminosae) and Glycyrrhiza glabra L. (Leguminosae)(Zhang et al., 2020), and the adverse reactions of this TCM formula are unclear. Shan et al. applied Qingre Baidu mixture to a rat model of refractory wound through oral administration with a dose of $40 \mathrm{mg}$ for every $\mathrm{kg}$ of body weight, and discovered that Qingre Baidu mixture could inhibit the biofilm formation of $P$. aeruginosa through downregulation of a self-inducer molecule AI2, important for regulation of biofilm development in $P$. aeruginosa (Shan et al., 2019). In addition, the QS inhibitory TCM Qi Gui Yin has exhibited downregulation of the expression of biofilm-related gene ArcA and IscU in P. aeruginosa (Ding et al., 2021a). The andrographolide compounds from $A$. paniculata (Burm.f.) Nees mentioned earlier could inhibit the biofilm formation of $P$. aeruginosa PA22 by $69-84 \%$ and PA247 by $23-56 \%$ at a concentration of $5 \mathrm{mg} / \mathrm{ml}$ (Tan Lim et al., 2021), and the chloroform extract of A. paniculata (Burm.f.) Nees inhibited the biofilm of $P$. aeruginosa PAO1 by $75.2 \%$ at a concentration of $1.25 \mathrm{mg} / \mathrm{ml}$ (Banerjee et al., 2017).

\section{Bactericidal Effects}

A variety of TCMs have shown bactericidal effects against respiratory pathogens by directly killing or inhibiting their growth (Ooi et al., 2006; Liu et al., 2007; Yamada et al., 2016), and some of them could enhance the in vitro antibacterial effects of antibiotics in treatment of MDR P. aeruginosa infections (Liu et al., 2007; Xu H. et al., 2019), possibly due to the enhanced stability of antibiotics by the reductive components of TCM (Gim et al., 2009; Chen et al., 2013; Matkowski et al., 2013; Sun W. et al., 2014; Chen et al., 2020), and the inhibitory effects of TCM on bacterial efflux pumps (Huang et al., 2015; Wang et al., 2018; Wang J. et al., 2019), suggesting that TCM could be a good alternative or complement for synthetic antibiotics. The minimum inhibitory concentration (MIC) and minimum bactericidal concentration (MBC) values of TCM against $P$. aeruginosa were summarized in Table 4.

Pyrrosia petiolosa (Christ et Bar.) Ching (Polypodiaceae) is a pteridophyte used as a TCM for the treatment of nephritis and bronchitis without causing adverse reactions (Cheng et al., 2020), and the ethanol extract of $P$. petiolosa (Christ et Bar.) Ching has shown significant inhibitory effects on P. aeruginosa ATCC27853 with an MIC and an MBC both at $5 \mathrm{mg} / \mathrm{ml}$ (Cheng et al., 2014). Zingiber striolatum Diels (Zingiberaceae) is a perennial plant widely distributed in southern China, and it has been used for many medicinal purposes for its antioxidant and antimicrobial properties without causing side effects (Sharifi-Rad et al., 2017). Tian et al. characterized the chemical components of the essential oil extracted from the rhizomes of $Z$. striolatum Diels by hydrodistillation, including $\beta$-phellandrene, sabinene, $\beta$-pinene, geranyl linalool, terpinen-4-ol, a-pinene and crypton, and determined the MIC of the essential oil against $P$. aeruginosa to be $3.12 \mathrm{mg} / \mathrm{ml}$ (Tian et al., 2020). The TCM Pentaherb formula is composed of the flower bud of L. japonica Thunb., Mentha canadensis L. (Lamiaceae), the root bark of Paeonia $\times$ suffruticosa 
TABLE 4 | Summaries of the bactericidal effects on TCM on $P$. aeruginosa.

\begin{tabular}{|c|c|c|c|}
\hline TCM & MIC & MBC & References \\
\hline Pyrrosia petiolosa (Christ et Bar.) Ching & $5 \mathrm{mg} / \mathrm{ml}$ & $5 \mathrm{mg} / \mathrm{ml}$ & Cheng et al. (2014) \\
\hline Rhizomes of Zingiber striolatum Diels & $3.12 \mathrm{mg} / \mathrm{ml}$ & $\begin{array}{l}\text { Not } \\
\text { specified }\end{array}$ & Tian et al. (2020) \\
\hline $\begin{array}{l}\text { Pentaherb formula composed of the flower bud of Lonicera japonica Thunb., Mentha canadensis L., the root bark } \\
\text { of Paeonia } \times \text { suffruticosa Andrews, Atractylodes lancea (Thunb.) DC. and the bark of Phellodendron chinense } \\
\text { C.K.Schneid }\end{array}$ & $1 \mathrm{mg} / \mathrm{ml}$ & $125 \mathrm{mg} / \mathrm{ml}$ & Hon et al. (2018) \\
\hline Phenylethanoid glycosides from Monochasma savatieri Franch. ex Maxim. & $0.5 \mathrm{mg} / \mathrm{ml}$ & $2 \mathrm{mg} / \mathrm{ml}$ & Liu et al. (2013) \\
\hline Sesquiterpenoids of Chimonanthus praecox (L.) Link & $\begin{array}{c}207.9-249.1 \\
\mathrm{ug} / \mathrm{ml}\end{array}$ & $\begin{array}{l}\text { Not } \\
\text { specified }\end{array}$ & Lou et al. (2018) \\
\hline Flavonoids from Morus nigra L. & Not specified & $2 \mathrm{mg} / \mathrm{ml}$ & Chen et al. (2017) \\
\hline Root bark of Paeonia $\times$ suffruticosa Andrews & 3-6 mg/L & $\begin{array}{l}\text { Not } \\
\text { specified }\end{array}$ & Liu et al. (2007) \\
\hline Ripe pericarp of Trichosanthes kirilowii Maxim. & $15-20 \mathrm{mg} / \mathrm{L}$ & $\begin{array}{l}\text { Not } \\
\text { specified }\end{array}$ & Liu et al. (2007) \\
\hline Unripe fruit of Prunus mume (Siebold) Siebold \& Zucc. & $1-3 \mathrm{mg} / \mathrm{L}$ & $\begin{array}{l}\text { Not } \\
\text { specified }\end{array}$ & Liu et al. (2007) \\
\hline Neolitsea cassia (L.) Kosterm. & $4-5 \mathrm{mg} / \mathrm{L}$ & $\begin{array}{l}\text { Not } \\
\text { specified }\end{array}$ & Liu et al. (2007) \\
\hline Root and rhizome of Sophora tonkinensis Gagnep. & $25-30 \mathrm{mg} / \mathrm{L}$ & $\begin{array}{l}\text { Not } \\
\text { specified }\end{array}$ & Liu et al. (2007) \\
\hline Bulb of Iphigenia indica (L.) A.Gray ex Kunth & $>30 \mathrm{mg} / \mathrm{L}$ & $\begin{array}{l}\text { Not } \\
\text { specified }\end{array}$ & Liu et al. (2007) \\
\hline Fruit of Forsythia suspensa (Thunb.) Vahl & $>30 \mathrm{mg} / \mathrm{L}$ & $\begin{array}{l}\text { Not } \\
\text { specified }\end{array}$ & Liu et al. (2007) \\
\hline Omphalia lapidescens Schroet & $>30 \mathrm{mg} / \mathrm{L}$ & $\begin{array}{l}\text { Not } \\
\text { specified }\end{array}$ & Liu et al. (2007) \\
\hline Bulb of Fritillaria thunbergii Miq. & $15-20 \mathrm{mg} / \mathrm{L}$ & $\begin{array}{l}\text { Not } \\
\text { specified }\end{array}$ & Liu et al. (2007) \\
\hline Root of Salvia miltiorrhiza Bunge & $20-25 \mathrm{mg} / \mathrm{L}$ & $\begin{array}{l}\text { Not } \\
\text { specified }\end{array}$ & Liu et al. (2007) \\
\hline Fuzheng Jiedu Huayu & $200 \mathrm{mg} / \mathrm{ml}$ & $\begin{array}{l}\text { Not } \\
\text { specified }\end{array}$ & Xu H. et al. (2019) \\
\hline
\end{tabular}

Andrews (Paeoniaceae), Atractylodes lancea (Thunb.) DC. (Compositae) and the bark of Phellodendron chinense C.K.Schneid (Rutaceae) with a mixture ratio of $2: 1: 2: 2: 2$, and it has been shown to effectively treat atopic dermatitis without causing side effects (Hon et al., 2007). Hon et al. determined the MIC and MBC of the water extracts of the Pentaherb formula against $P$. aeruginosa ATCC 27853 to be $1 \mathrm{mg} / \mathrm{ml}$ and $125 \mathrm{mg} / \mathrm{ml}$, respectively (Hon et al., 2018). Monochasma savatieri Franch. ex Maxim. (Orobanchaceae) is a perennial botanical drug widely used in TCM for treatment of many inflammatory diseases, and no toxic effects of this botanical drug have been documented (Gao H. et al., 2017). Liu et al. found that P. aeruginosa ATCC 27853 was sensitive to the phenylethanoid glycosides from $M$. savatieri Franch. ex Maxim., which had an MIC of $0.5 \mathrm{mg} / \mathrm{ml}$ and an MBC of $2 \mathrm{mg} / \mathrm{ml}$ (Liu et al., 2013). Furthermore, they demonstrated that the survival rates of the mice pretreated with phenylethanoid glycosides at a dose of $180 \mathrm{mg}$ for every $\mathrm{kg}$ of body weight were significantly increased by $75 \%$ compared to untreated mice following $P$. aeruginosa intraperitoneal infections, and the pretreatment of this drug could reduce the bacterial burden in the lung tissues of the $P$. aeruginosa lung-infected mice (Liu et al., 2013). Chimonanthus praecox (L.) Link (Calycanthaceae), also known as wintersweet, is a deciduous shrub used for treatment of coughs, rheumatic arthritis, throat wounds, dizziness, nausea and fever, and its side effects are not well-characterized (Kitagawa et al., 2016). The sesquiterpenoids isolated from the ethyl acetate extract of C. praecox (L.) Link stems and roots have been reported to possess antibacterial effects against $P$. aeruginosa ATCC 10145 with an MIC of 207.9-249.1 ug/ml (Lou et al., 2018). Mulberry is not only a fruit with a lot of nutrients but also a TCM comprising of many antioxidant and anti-inflammatory compounds (Huang et al., 2013), and the MBC of the flavonoids from the fruits of black mulberry Morus nigra L. (Moraceae) against $P$. aeruginosa was assessed to be $2 \mathrm{mg} / \mathrm{ml}$ (Chen et al., 2017). A research group from Taiwan discovered 10 ethanol extracts of Chinese herbal medicines including the root bark of Paeonia $\times$ suffruticosa Andrews, the ripe pericarp of Trichosanthes kirilowii Maxim. (Cucurbitaceae; Trichosanthis Pericarpium), the unripe fruit of Prunus mume (Siebold) Siebold \& Zucc. (Rosaceae), Neolitsea cassia (L.). Kosterm. (Lauraceae; Ramulus Cinnamomi), the root and rhizome of Sophora tonkinensis Gagnep. (Leguminosae; Sophorae Tonkinensis radix et rhizome), the bulb of Iphigenia indica (L.) A.Gray ex Kunth (Colchicaceae), the fruit of $F$. suspensa (Thunb.) Vahl, Omphalia lapidescens Schroet (Leiwan), the bulb of Fritillaria thunbergii Miq. (Liliaceae; Fritillariae Bulbus), and the root of $S$. miltiorrhiza Bunge possessed a broad-spectrum of bactericidal activity against antibiotic-resistant $P$. aeruginosa strains. Among these herbal medicines, $N$. cassia (L.) Kosterm. was found to synergize with tetracycline, gentamycin and streptomycin to inhibit $P$. 
TABLE 5 | Summaries of TCM-modulated host immune responses during $P$. aeruginosa infections.

\begin{tabular}{|c|c|c|c|}
\hline TCM & $\begin{array}{l}\text { Effects } \\
\text { on immune responses }\end{array}$ & Mechanisms & References \\
\hline $\begin{array}{l}\text { Qingfei } \\
\text { Xiaoyan Wan }\end{array}$ & Reduction of lung inflammation & $\begin{array}{l}\text { Suppression of PI3K/AKT and Ras/MAPK pathways, and } \\
\text { impairment of production of TNF- } \alpha \text {, IL-6) and RANTES }\end{array}$ & Hou et al. (2016) \\
\hline $\begin{array}{l}\text { Xiao Chai Hu } \\
\text { Tang }\end{array}$ & $\begin{array}{l}\text { Accumulation of polymorphonuclear leukocytes and } \\
\text { promotion the phagocytic activity of macrophages }\end{array}$ & Not specified & Kawakita et al. (1987b) \\
\hline $\begin{array}{l}\text { Shufengjiedu } \\
\text { capsule }\end{array}$ & Alleviation of lung inflammation & Inhibition of ERK pathway and NF-kB activation & Li et al. (2017) \\
\hline Shiunko & Promotion of epithelization in skin wound & $\begin{array}{l}\text { Enhancement of fibroblast proliferation and collagen } \\
\text { production, and suppression of skin inflammation }\end{array}$ & $\begin{array}{l}\text { Huang et al. (2004); Yan et al. } \\
\text { (2015); Imai et al. (2019) }\end{array}$ \\
\hline Qi Gui Yin & $\begin{array}{l}\text { Increase of B cell response and downregulation of } \\
\text { inflammation }\end{array}$ & $\begin{array}{l}\text { Enhancement of antibody reactivity to } \beta \text {-lactamases and } \\
\text { reduction of the levels of } \mathrm{IL}-1 \beta \text { and Th1/Th2 ratio }\end{array}$ & Kong et al. (2015) \\
\hline $\begin{array}{l}\text { Qingre Baidu } \\
\text { mixture }\end{array}$ & Promotion of angiogenesis and wound healing & $\begin{array}{l}\text { Upregulation of the expression of HIF-1a, HIF-2a and } \\
\text { VEGF }\end{array}$ & Shan et al. (2019) \\
\hline
\end{tabular}

aeruginosa growth (Liu et al., 2007). Of note, S. tonkinensis Gagnep. may cause toxic effects including hematotoxicity, neurotoxicity, and immunotoxicity (Zhang et al., 2021), and the bulb of $F$. thunbergii Miq. exhibited toxicity to rats at the doses greater than $1 \mathrm{mg}$ for every $\mathrm{kg}$ of body weight (Li et al., 2014). The side effects of other TCM botanical drugs listed above have not been reported. Fuzheng Jiedu Huayu formula consists of eight Chinese botanical drugs, including S. baicalensis Georgi, F. suspensa (Thunb.) Vahl, Echinops latifolius Tausch (Compositae), T. kirilowii Maxim., Panax quinquefolius L. (Araliaceae), P. scabiosifolia Link, and Coix lacryma-jobi var. ma-yuen (Rom.Caill.) Stapf (Poaceae) with a mixture ratio of 2.5: 2.5:2.5:2.5:5:1:5:5 (Xu H. et al., 2019). Furthermore, the Fuzheng Jiedu Huayu formula decoction has been applied to treat elderly patients with pneumonia in clinical trials, and no obvious adverse reactions were manifested (Xu et al., 2018). Xu et al. revealed that the Fuzheng Jiedu Huayu decoction with an MIC of $200 \mathrm{mg} / \mathrm{ml}$ against $P$. aeruginosa combined with Imipenem/cilastatin sodium could enhance the in vitro bactericidal and bacteriostatic effects of Imipenem/cilastatin sodium on MDR $P$. aeruginosa (Xu $\mathrm{H}$. et al., 2019).

\section{Immunomodulation}

A tightly controlled immune response ensures an effective host defense against microbial infection and maintenance of tissue homeostasis (Liu and Cao, 2016). Excessive immune response causes host tissue damage, septic shock and ultimately death (Bortolotti et al., 2018). On the other hand, deficient immune response results in chronic and persistent bacterial infections (Smith et al., 2009). Immunomodulation is an important function of TCM, which activates or suppresses the immune responses of a variety of immune cells, including macrophages (Jian et al., 2019), dendritic cells (Chen et al., 2006), T cells (Guo et al., 2015), B cells (Kawakita et al., 1987a) and NK cells (Hoffman et al., 2020). The immunomodulatory effects of TCM on host immunity in the context of $P$. aeruginosa infections have been evaluated in past decade (Table 5)(Kong et al., 2015; Hou et al., 2016; Li et al., 2017).

Qingfei Xiaoyan Wan, a TCM pill, consists of E. sinica Stapf, Gypsum Fibrosum, Pheretima (earthworm), the ripe fruit of Arctium lappa L. (Compositae; Arctii Fructus), the seed of
Descurainia sophia (L.) Webb ex Prantl (Brassicaceae), Bovis Calculus Artifactus (Artificial ox bezoar), the seed of $P$. armeniaca L. and Cornu Saigae Tataricae (Hou et al., 2016), and it has been used in China for treatment of asthma and respiratory tract infections without induing obvious side effects (Zhao et al., 2013). A study by Hou et al. evaluated the effects of Qingfei Xiaoyan Wan suspended in distilled water on a mouse model of $P$. aeruginosa-induced acute pneumonia, and they demonstrated that the oral administration of Qingfei Xiaoyan Wan (18 g for every kg of body weight per day) for 1 week could reduce the $P$. aeruginosa PAK-induced lung inflammation by decreasing the production of cytokines (TNF- $\alpha$ and IL-6) and chemokine (RANTES) in lung tissues, significantly ameliorating lung injury. Importantly, the authors identified arctigenin, cholic acid, chlorogenic acid and sinapic acid to be the antiinflammatory ingredients of Qingfei Xiaoyan Wan, which suppressed the expression of the regulatory proteins in $\mathrm{PI} 3 \mathrm{~K} /$ AKT and Ras/MAPK pathways (Hou et al., 2016). Xiao Chai Hu Tang is a 7-ingredient TCM consisting of the tuber of Pinellia ternata (Thunb.) Makino (Araceae), the fruit of Ziziphus jujuba Mill. (Rhamnaceae), and the root of S. baicalensis Georgi, Bupleurum chinense DC. (Apiaceae), Panax ginseng C.A.Mey. (Araliaceae), Glycyrrhiza glabra L. (Leguminosae) and Zingiber officinale Roscoe (Zingiberaceae), and it is widely used for treatment of respiratory, hepatic and gastrointestinal diseases (Hsu et al., 2006). However, Xiao Chai Hu Tang has been reported to cause hepatotoxicity due to overdose or long-term use (Gao X. et al., 2017). Kawakita et al. demonstrated that the water extract of Xiao Chai Hu Tang (100 mg for every kg of body weight) was able to protect mice from intraperitoneal infections with $P$. aeruginosa by promoting the accumulation of polymorphonuclear leukocytes and enhancing the phagocytic activity of macrophages (Kawakita et al., 1987b). The underlying mechanisms need to the further explored. Shufengjiedu capsule is an oral Chinese patent medicine that has been extensively utilized for treatment of respiratory infectious diseases and chronic obstructive pulmonary disease without causing serious adverse reactions (Xia et al., 2020). In the context of $P$. aeruginosa pulmonary infections, pretreatment of the power suspension from Shufengjiedu capsule with a dose of $0.09 \mathrm{~g}$ for every $\mathrm{kg}$ of body weight by intragastric gavage was 
reported to reduce the $P$. aeruginosa PAK-induced lung inflammation in mice through inhibition of ERK pathway and NF- $\kappa B$ activation, leading to decreased IL-6 production and alleviated lung injury (Li et al., 2017). Furthermore, the active components of Shufengjiedu capsule including verbenalin, phillyrin and emodin were identified to contribute to the regulation of ERK pathway (Li et al., 2017). Pseudomonas aeruginosa is one of the common pathogens isolated from chronic wounds, and the infections by $P$. aeruginosa affect wound healing (Serra et al., 2015). Shiunko ointment is a traditional botanic formula used for treatment of wounded skin without causing undesirable side effects in China and Japan (Higaki et al., 1999), and it has been found to accelerate the epithelization of wounded skin infected with $P$. aeruginosa (Huang et al., 2004). The mechanisms underlying the Shiunkomodulated epithelization possibly being through enhancing fibroblast proliferation and collagen production, and suppressing skin inflammation (Yan et al., 2015; Imai et al., 2019). In addition to inhibition of $P$. aeruginosa QS and biofilm formation, Qi Gui Yin decoction (9.9 $\mathrm{g}$ for every $\mathrm{kg}$ of body weight) was also identified to promote host immune response to $P$. aeruginosa infections by enhancing the antibody reactivity to $\beta$-lactamases, including VIM-1, SPM-1, and TEM-1, and manifested anti-inflammatory effects by reducing the levels of IL- $1 \beta$ and Th1/Th2 ratio in a rat model of abdominal infection (Kong et al., 2015). Qingre Baidu mixture was reported to promote angiogenesis and wound healing in a rat model of refractory wounds during $P$. aeruginosa infection by upregulating the expression of HIF-1 $\alpha$, HIF-2 $\alpha$ and VEGF (Shan et al., 2019).

\section{CONCLUSION}

Antibiotic resistance has led to a significant challenge for treatment of $P$. aeruginosa infections in clinical settings. Many alternative therapeutic options have been developed over the past decade and demonstrated promising antimicrobial effects against antibiotic-resistant $P$. aeruginosa infections in vitro or in animal models. However, only a few of them has proceeded to clinical trials. By contrast, TCM has been clinically practiced over thousands of years in China with its unique system of theories, diagnostics and therapies for many kinds of diseases. In particular, the Chinese herbal medicines have shown great clinical efficacies in prevention and treatment of chronic infectious diseases. Importantly, TCM was reported to effectively control the infections caused by the clinical isolates of $P$. aeruginosa strains with antibiotic resistance through inhibiting the expression of QS regulatory proteins, disrupting biofilm structure and maturation, directly killing or inhibiting bacterial growth, and modulating host immune responses, including acceleration of the leukocyte accumulation to infection sites, enhancement of macrophage phagocytosis, reduction of host inflammatory response and promotion of wound epithelization. Moreover, some studies indicated that combination of TCM and antibiotics could enhance the effects of antibiotics against $P$. aeruginosa infections, which could be attributed to the antibiotic properties of TCM and the reductive components of TCM stabilizing the antibiotics from degradation (Gim et al., 2009; Chen et al., 2013; Matkowski et al., 2013; Sun W. et al., 2014; Chen et al., 2020). In addition, many TCM active compounds have shown inhibitory effects on the gene expression of bacterial efflux pumps, which could also enhance the antimicrobial effects of antibiotics (Huang et al., 2015; Wang et al., 2018; Wang J. et al., 2019). For instance, baicalin was found to significantly inhibit the mRNA transcription of MsrA efflux pump in Staphylococcus saprophyticus (Wang J. et al., 2019). The emodin from Rheum palmatum L. (Polygonaceae), the schizandrin from Schisandra chinensis (Turcz.) Baill. (Schisandraceae), the berberine from Berberis vulgaris L. (Berberidaceae), and baicalin were identified to significantly reduce the expression of the efflux pump gene hefA in Helicobacter pylori (Huang et al., 2015). However, the role of TCM in regulation of the efflux pumps in $P$. aeruginosa has not yet been elucidated, which could be a direction for future research. Altogether, TCM emerges as a promising complementary and alternative therapeutic approach for treatment of $P$. aeruginosa infections. However, due to the multiple gradients and targets of TCM, the mechanisms involved in the TCMinhibited $P$. aeruginosa infections are incompletely understood. Future studies need to focus on investigating the effects of a single active component of TCM on $P$. aeruginosa and host, which gives a clearer understanding of the drug-host and drug-microbe interactions, allowing development of the TCM with reduced side effects and improved effectiveness in clinical trials.

\section{AUTHOR CONTRIBUTIONS}

$\mathrm{ZP}$ contributed to the study design, data collection and interpretation, and article writing. QZ contributed to article writing and revision. All the authors read and approved the final article.

\section{FUNDING}

This study was funded by the National Natural Science Foundation of China (Grant No. 82002112).

\section{ACKNOWLEDGMENTS}

The figures in this study were created with BioRender.com. 


\section{REFERENCES}

Alhede, M., Bjarnsholt, T., Givskov, M., and Alhede, M. (2014). Pseudomonas aeruginosa Biofilms: Mechanisms of Immune Evasion. Adv. Appl. Microbiol. 86, 1-40. doi:10.1016/B978-0-12-800262-9.00001-9

Banerjee, M., Moulick, S., Bhattacharya, K. K., Parai, D., Chattopadhyay, S., and Mukherjee, S. K. (2017). Attenuation of Pseudomonas aeruginosa Quorum Sensing, Virulence and Biofilm Formation by Extracts of Andrographis Paniculata. Microb. Pathog. 113, 85-93. doi:10.1016/j.micpath.2017.10.023

Bardoel, B. W., van Kessel, K. P., van Strijp, J. A., and Milder, F. J. (2012). Inhibition of Pseudomonas aeruginosa Virulence: Characterization of the AprA-AprI Interface and Species Selectivity. J. Mol. Biol. 415, 573-583. doi:10.1016/ j.jmb.2011.11.039

Bodey, G. P., Bolivar, R., Fainstein, V., and Jadeja, L. (1983). Infections Caused by Pseudomonas aeruginosa. Rev. Infect. Dis. 5, 279-313. doi:10.1093/clinids/ 5.2 .279

Bortolotti, P., Faure, E., and Kipnis, E. (2018). Inflammasomes in Tissue Damages and Immune Disorders after Trauma. Front. Immunol. 9, 1900. doi:10.3389/ fimmu.2018.01900

Botelho, J., Grosso, F., and Peixe, L. (2019). Antibiotic Resistance in Pseudomonas aeruginosa - Mechanisms, Epidemiology and Evolution. Drug Resist. Updat 44, 100640. doi:10.1016/j.drup.2019.07.002

Cass, S. P. (2017). Alzheimer's Disease and Exercise: A Literature Review. Curr. Sports Med. Rep. 16, 19-22. doi:10.1249/JSR.0000000000000332

Chen, C. Y., Li, H., Yuan, Y. N., Dai, H. Q., and Yang, B. (2013). Antioxidant Activity and Components of a Traditional Chinese Medicine Formula Consisting of Crataegus Pinnatifida and Salvia Miltiorrhiza. BMC Complement. Altern. Med. 13, 99. doi:10.1186/1472-6882-13-99

Chen, H., Yu, W., Chen, G., Meng, S., Xiang, Z., and He, N. (2017). Antinociceptive and Antibacterial Properties of Anthocyanins and Flavonols from Fruits of Black and Non-black Mulberries. Molecules 23, 4. doi:10.3390/ molecules23010004

Chen, S. Y., Gao, Y., Sun, J. Y., Meng, X. L., Yang, D., Fan, L. H., et al. (2020). Traditional Chinese Medicine: Role in Reducing $\beta$-Amyloid, Apoptosis, Autophagy, Neuroinflammation, Oxidative Stress, and Mitochondrial Dysfunction of Alzheimer's Disease. Front. Pharmacol. 11, 497. doi:10.3389/ fphar.2020.00497

Chen, X., Yang, L., Howard, O. M., and Oppenheim, J. J. (2006). Dendritic Cells as a Pharmacological Target of Traditional Chinese Medicine. Cell Mol Immunol 3, 401-410.

Cheng, D., Zhang, Y., Gao, D., and Zhang, H. (2014). Antibacterial and antiinflammatory activities of extract and fractions from Pyrrosia petiolosa (Christ et Bar.) Ching. J. Ethnopharmacol 155, 1300-1305. doi:10.1016/j.jep.2014.07.029

Cheng, J., Cao, M., Yi, S., Tao, Y., Wang, L., Zhang, A., et al. (2020). Antiinflammatory and Antibacterial Activities of P. Petiolosa (Christ) Ching Ethyl Acetate Extract against S. aureus in Mice. Pak J. Pharm. Sci. 33, 2047-2052. doi:10.36721/PJPS.2020.33.5.REG.2047-2052.1

Daniels, R., Vanderleyden, J., and Michiels, J. (2004). Quorum sensing and Swarming Migration in Bacteria. FEMS Microbiol. Rev. 28, 261-289. doi:10.1016/j.femsre.2003.09.004

Ding, J., Gao, X., Gui, H., Ding, X., Lu, Y., An, S., et al. (2021a). Proteomic Analysis of Proteins Associated with Inhibition of Pseudomonas aeruginosa Resistance to Imipenem Mediated by the Chinese Herbal Medicine Qi Gui Yin. Microb. Drug Resist. 27, 462-470. doi:10.1089/mdr.2020.0110

Ding, J., Gao, X., Zhang, F., Zhou, Y., Li, S., Lu, Y., et al. (2021b). Toxicological Safety Evaluation of Qiguiyin Formula in Rats at the Treatment Phase and Recovery Phase. J. Ethnopharmacol 279, 114364. doi:10.1016/j.jep.2021.114364

Donlan, R. M. (2002). Biofilms: Microbial Life on Surfaces. Emerg. Infect. Dis. 8, 881-890. doi:10.3201/eid0809.020063

Du, H. Z., Hou, X. Y., Miao, Y. H., Huang, B. S., and Liu, D. H. (2020). Traditional Chinese Medicine: an Effective Treatment for 2019 Novel Coronavirus Pneumonia (NCP). Chin. J. Nat. Med. 18, 206-210. doi:10.1016/S18755364(20)30022-4

Fu, B., Wu, Q., Dang, M., Bai, D., Guo, Q., Shen, L., et al. (2017). Inhibition of Pseudomonas aeruginosa Biofilm Formation by Traditional Chinese Medicinal Herb Herba Patriniae. Biomed. Res. Int. 2017, 9584703. doi:10.1155/2017/ 9584703
Gao, H., Cui, Y., Kang, N., Liu, X., Liu, Y., Zou, Y., et al. (2017a). Isoacteoside, a Dihydroxyphenylethyl Glycoside, Exhibits Anti-inflammatory Effects through Blocking Toll-like Receptor 4 Dimerization. Br. J. Pharmacol. 174, 2880-2896. doi:10.1111/bph.13912

Gao, X., Liang, M., Fang, Y., Zhao, F., Tian, J., Zhang, X., et al. (2017b). Deciphering the Differential Effective and Toxic Responses of Bupleuri Radix Following the Induction of Chronic Unpredictable Mild Stress and in Healthy Rats Based on Serum Metabolic Profiles. Front. Pharmacol. 8, 995. doi:10.3389/ fphar.2017.00995

Ghafoor, A., Hay, I. D., and Rehm, B. H. (2011). Role of Exopolysaccharides in Pseudomonas aeruginosa Biofilm Formation and Architecture. Appl. Environ. Microbiol. 77, 5238-5246. doi:10.1128/AEM.00637-11

Gim, G. T., Kim, H. M., Kim, J., Kim, J., Whang, W. W., and Cho, S. H. (2009). Antioxidant Effect of Tianwang Buxin Pills a Traditional Chinese Medicine Formula: Double-Blind, Randomized Controlled Trial. Am. J. Chin. Med. 37, 227-239. doi:10.1142/S0192415X09006795

Glessner, A., Smith, R. S., Iglewski, B. H., and Robinson, J. B. (1999). Roles of Pseudomonas aeruginosa Las and Rhl Quorum-sensing Systems in Control of Twitching Motility. J. Bacteriol. 181, 1623-1629. doi:10.1128/JB.181.5.16231629.1999

Gong, L., Zou, W., Zheng, K., Shi, B., and Liu, M. (2021). The Herba Patriniae (Caprifoliaceae): A Review on Traditional Uses, Phytochemistry, Pharmacology and Quality Control. J. Ethnopharmacol 265, 113264. doi:10.1016/ j.jep.2020.113264

Guo, A., He, D., Xu, H. B., Geng, C. A., and Zhao, J. (2015). Promotion of Regulatory T Cell Induction by Immunomodulatory Herbal Medicine Licorice and its Two Constituents. Sci. Rep. 5, 14046. doi:10.1038/srep14046

Ha, D. G., and O'Toole, G. A. (2015). c-di-GMP and its Effects on Biofilm Formation and Dispersion: a Pseudomonas Aeruginosa Review. Microbiol. Spectr. 3, MB-0003-2014. doi:10.1128/microbiolspec.MB-0003-2014

Hao, P., Jiang, F., Cheng, J., Ma, L., Zhang, Y., and Zhao, Y. (2017). Traditional Chinese Medicine for Cardiovascular Disease: Evidence and Potential Mechanisms. J. Am. Coll. Cardiol. 69, 2952-2966. doi:10.1016/ j.jacc.2017.04.041

Higaki, S., Kitagawa, T., Morohashi, M., and Yamagishi, T. (1999). Efficacy of Shiunko for the Treatment of Atopic Dermatitis. J. Int. Med. Res. 27, 143-147. doi:10.1177/030006059902700305

Hoffman, R. D., Li, C. Y., He, K., Wu, X., He, B. C., He, T. C., et al. (2020). Chinese Herbal Medicine and its Regulatory Effects on Tumor Related T Cells. Front. Pharmacol. 11, 492. doi:10.3389/fphar.2020.00492

Høiby, N., Bjarnsholt, T., Givskov, M., Molin, S., and Ciofu, O. (2010). Antibiotic Resistance of Bacterial Biofilms. Int. J. Antimicrob. Agents 35, 322-332. doi:10.1016/j.ijantimicag.2009.12.011

Hon, K. L., Ip, M., Wong, C. K., Chan, B. C. L., Leung, P. C., and Leung, T. F. (2018). In Vitro antimicrobial Effects of a Novel Pentaherbs Concoction for Atopic Dermatitis. J. Dermatolog Treat. 29, 235-237. doi:10.1080/ 09546634.2017.1395804

Hon, K. L., Leung, T. F., Ng, P. C., Lam, M. C., Kam, W. Y., Wong, K. Y., et al. (2007). Efficacy and Tolerability of a Chinese Herbal Medicine Concoction for Treatment of Atopic Dermatitis: a Randomized, Double-Blind, PlaceboControlled Study. Br. J. Dermatol. 157, 357-363. doi:10.1111/j.13652133.2007.07941.x

Hou, Y., Nie, Y., Cheng, B., Tao, J., Ma, X., Jiang, M., et al. (2016). Qingfei Xiaoyan Wan, a Traditional Chinese Medicine Formula, Ameliorates Pseudomonas Aeruginosa-Induced Acute Lung Inflammation by Regulation of PI3K/AKT and Ras/MAPK Pathways. Acta Pharm. Sin B 6, 212-221. doi:10.1016/ j.apsb.2016.03.002

Howes, M. R., Fang, R., and Houghton, P. J. (2017). Effect of Chinese Herbal Medicine on Alzheimer's Disease. Int. Rev. Neurobiol. 135, 29-56. doi:10.1016/ bs.irn.2017.02.003

Hsu, L. M., Huang, Y. S., Tsay, S. H., Chang, F. Y., and Lee, S. D. (2006). Acute Hepatitis Induced by Chinese Hepatoprotective Herb, Xiao-Chai-HuTang. J. Chin. Med. Assoc. 69, 86-88. doi:10.1016/S1726-4901(09) 70119-4

Huang, H. P., Ou, T. T., and Wang, C. J. (2013). Mulberry ( Sang Shèn Zǐ) and its Bioactive Compounds, the Chemoprevention Effects and Molecular Mechanisms In Vitro and In Vivo. J. Tradit Complement. Med. 3, 7-15. doi:10.4103/2225-4110.106535 
Huang, K. F., Hsu, Y. C., Lin, C. N., Tzeng, J. I., Chen, Y. W., and Wang, J. J. (2004). Shiunko Promotes Epithelization of Wounded Skin. Am. J. Chin. Med. 32, 389-396. doi:10.1142/S0192415X04002041

Huang, Y. Q., Huang, G. R., Wu, M. H., Tang, H. Y., Huang, Z. S., Zhou, X. H., et al. (2015). Inhibitory Effects of Emodin, Baicalin, Schizandrin and Berberine on hefA Gene: Treatment of Helicobacter Pylori-Induced Multidrug Resistance. World J. Gastroenterol. 21, 4225-4231. doi:10.3748/wjg.v21.i14.4225

Imai, K., Kato, H., Taguchi, Y., and Umeda, M. (2019). Biological Effects of Shikonin in Human Gingival Fibroblasts via ERK 1/2 Signaling Pathway. Molecules 24, 3542. doi:10.3390/molecules24193542

Imberty, A., and Varrot, A. (2008). Microbial Recognition of Human Cell Surface Glycoconjugates. Curr. Opin. Struct. Biol. 18, 567-576. doi:10.1016/ j.sbi.2008.08.001

Jamal, M., Ahmad, W., Andleeb, S., Jalil, F., Imran, M., Nawaz, M. A., et al. (2018). Bacterial Biofilm and Associated Infections. J. Chin. Med. Assoc. 81, 7-11. doi:10.1016/j.jcma.2017.07.012

Jayakumar, T., Hsieh, C. Y., Lee, J. J., and Sheu, J. R. (2013). Experimental and Clinical Pharmacology of Andrographis Paniculata and its Major Bioactive Phytoconstituent Andrographolide. Evid. Based Complement. Alternat Med. 2013, 846740. doi:10.1155/2013/846740

Jayaseelan, S., Ramaswamy, D., and Dharmaraj, S. (2014). Pyocyanin: Production, Applications, Challenges and New Insights. World J. Microbiol. Biotechnol. 30, 1159-1168. doi:10.1007/s11274-013-1552-5

Jian, X., Liu, Y., Zhao, Z., Zhao, L., Wang, D., and Liu, Q. (2019). The Role of Traditional Chinese Medicine in the Treatment of Atherosclerosis through the Regulation of Macrophage Activity. Biomed. Pharmacother. 118, 109375. doi:10.1016/j.biopha.2019.109375

Jiang, M., Sheng, F., Zhang, Z., Ma, X., Gao, T., Fu, C., et al. (2021). Andrographis Paniculata (Burm.f.) Nees and its Major Constituent Andrographolide as Potential Antiviral Agents. J. Ethnopharmacol 272, 113954. doi:10.1016/ j.jep.2021.113954

Kariminik, A., Baseri-Salehi, M., and Kheirkhah, B. (2017). Pseudomonas aeruginosa Quorum Sensing Modulates Immune Responses: An Updated Review Article. Immunol. Lett. 190, 1-6. doi:10.1016/j.imlet.2017.07.002

Kawakita, T., Yamada, A., Kumazawa, Y., and Nomoto, K. (1987a). Functional Maturation of Immature B Cells Accumulated in the Periphery by an Intraperitoneal Administration of a Traditional Chinese Medicine, XiaoChai-Hu-Tang (Japanese Name: Shosaiko-To). Immunopharmacol Immunotoxicol 9, 299-317. doi:10.3109/08923978709035216

Kawakita, T., Yamada, A., Mitsuyama, M., Kumazawa, Y., and Nomoto, K. (1987b). Protective Effect of a Traditional Chinese Medicine, Xiao-Chai-HuTang (Japanese Name: Shosaiko-To), on Pseudomonas aeruginosa Infection in Mice. Immunopharmacol Immunotoxicol 9, 523-540. doi:10.3109/ 08923978709035230

Kitagawa, N., Ninomiya, K., Okugawa, S., Motaia, C., Nakanishi, Y., Yoshikawa, M., et al. (2016). Quantitative Determination of Principal Alkaloid and Flavonoid Constituents in Wintersweet, the Flower Buds of Chimonanthuspraecox. Nat. Prod. Commun. 11, 953-956. doi:10.1177/1934578x1601100721

Koh, K. H., and Tham, F. Y. (2011). Screening of Traditional Chinese Medicinal Plants for Quorum-sensing Inhibitors Activity. J. Microbiol. Immunol. Infect. 44, 144-148. doi:10.1016/j.jmii.2009.10.001

Kong, F., Luan, Y., Zhang, Z. H., Cheng, G. H., Qi, T. G., and Sun, C. (2014). Baicalin Protects the Myocardium from Reperfusion-Induced Damage in Isolated Rat Hearts via the Antioxidant and Paracrine Effect. Exp. Ther. Med. 7, 254-259. doi:10.3892/etm.2013.1369

Kong, L. B., Ma, Q., Gao, J., Qiu, G. S., Wang, L. X., Zhao, S. M., et al. (2015). Effect of Qiguiyin Decoction on Multidrug-Resistant Pseudomonas aeruginosa Infection in Rats. Chin. J. Integr. Med. 21, 916-921. doi:10.1007/s11655-0152089-2

Le Bars, P. L., Katz, M. M., Berman, N., Itil, T. M., Freedman, A. M., and Schatzberg, A. F. (1997). A Placebo-Controlled, Double-Blind, Randomized Trial of an Extract of Ginkgo Biloba for Dementia. North American EGb Study Group. JAMA 278, 1327-1332. doi:10.1001/jama.278.16.1327

Lee, J., Wu, J., Deng, Y., Wang, J., Wang, C., Wang, J., et al. (2013). A Cell-Cell Communication Signal Integrates Quorum Sensing and Stress Response. Nat. Chem. Biol. 9, 339-343. doi:10.1038/nchembio.1225
Lee, J., and Zhang, L. (2015). The Hierarchy Quorum Sensing Network in Pseudomonas aeruginosa. Protein Cell 6, 26-41. doi:10.1007/s13238-0140100-x

Lee, W., Ku, S. K., and Bae, J. S. (2015). Antiplatelet, Anticoagulant, and Profibrinolytic Activities of Baicalin. Arch. Pharm. Res. 38, 893-903. doi:10.1007/s12272-014-0410-9

Li, L. C., Zhang, Z. H., Zhou, W. C., Chen, J., Jin, H. Q., Fang, H. M., et al. (2020). Lianhua Qingwen Prescription for Coronavirus Disease 2019 (COVID-19) Treatment: Advances and Prospects. Biomed. Pharmacother. 130, 110641. doi:10.1016/j.biopha.2020.110641

Li, Y., Chang, N., Han, Y., Zhou, M., Gao, J., Hou, Y., et al. (2017). Antiinflammatory Effects of Shufengjiedu Capsule for Upper Respiratory Infection via the ERK Pathway. Biomed. Pharmacother. 94, 758-766. doi:10.1016/j.biopha.2017.07.118

Li, Z., Qiao, Y., Li, J., An, C., Hu, K., and Tang, M. (2014). Acute and Sub-chronic Toxicity Studies of the Extract of Thunberg Fritillary Bulb. Regul. Toxicol. Pharmacol. 68, 370-377. doi:10.1016/j.yrtph.2014.01.007

Liao, Y. H., Li, C. I., Lin, C. C., Lin, J. G., Chiang, J. H., and Li, T. C. (2017). Traditional Chinese Medicine as Adjunctive Therapy Improves the Long-Term Survival of Lung Cancer Patients. J. Cancer Res. Clin. Oncol. 143, 2425-2435. doi:10.1007/s00432-017-2491-6

Lin, J., Cheng, J., Wang, Y., and Shen, X. (2018). The Pseudomonas Quinolone Signal (PQS): Not Just for Quorum Sensing Anymore. Front Cel Infect Microbiol 8, 230. doi:10.3389/fcimb.2018.00230

Liu, C. S., Cham, T. M., Yang, C. H., Chang, H. W., Chen, C. H., and Chuang, L. Y. (2007). Antibacterial Properties of Chinese Herbal Medicines against Nosocomial Antibiotic Resistant Strains of Pseudomonas aeruginosa in Taiwan. Am. J. Chin. Med. 35, 1047-1060. doi:10.1142/S0192415X07005508

Liu, H., Ding, X. F., Guo, R., Zhao, M. F., Deng, D., Hao, Y., et al. (2020). Effects and Safety of Tanreqing Injection on Viral Pneumonia: A Protocol for Systematic Review and Meta-Analysis. Medicine (Baltimore) 99, e21808. doi:10.1097/ MD.0000000000021808

Liu, J., and Cao, X. (2016). Cellular and Molecular Regulation of Innate Inflammatory Responses. Cel Mol Immunol 13, 711-721. doi:10.1038/ cmi.2016.58

Liu, Y. L., He, W. J., Mo, L., Shi, M. F., Zhu, Y. Y., Pan, S., et al. (2013). Antimicrobial, Anti-inflammatory Activities and Toxicology of Phenylethanoid Glycosides from Monochasma Savatieri Franch. Ex Maxim. J. Ethnopharmacol 149, 431-437. doi:10.1016/j.jep.2013.06.042

Lou, H. Y., Zhang, Y., Ma, X. P., Jiang, S., Wang, X. P., Yi, P., et al. (2018). Novel Sesquiterpenoids Isolated from Chimonanthus Praecox and Their Antibacterial Activities. Chin. J. Nat. Med. 16, 621-627. doi:10.1016/S1875-5364(18)30100-6

Luo, J., Dong, B., Wang, K., Cai, S., Liu, T., Cheng, X., et al. (2017). Baicalin Inhibits Biofilm Formation, Attenuates the Quorum Sensing-Controlled Virulence and Enhances Pseudomonas Aeruginosa Clearance in a Mouse Peritoneal Implant Infection Model. PLoS One 12, e0176883. doi:10.1371/journal.pone.0176883

Lyczak, J. B., Cannon, C. L., and Pier, G. B. (2002). Lung Infections Associated with Cystic Fibrosis. Clin. Microbiol. Rev. 15, 194-222. doi:10.1128/cmr.15.2.194222.2002

Ma, Y., Chen, M., Guo, Y., Liu, J., Chen, W., Guan, M., et al. (2019). Prevention and Treatment of Infectious Diseases by Traditional Chinese Medicine: a Commentary. APMIS 127, 372-384. doi:10.1111/apm.12928

Masuda, N., Sakagawa, E., Ohya, S., Gotoh, N., Tsujimoto, H., and Nishino, T. (2000). Substrate Specificities of MexAB-OprM, MexCD-OprJ, and MexXYoprM Efflux Pumps in Pseudomonas aeruginosa. Antimicrob. Agents Chemother. 44, 3322-3327. doi:10.1128/aac.44.12.3322-3327.2000

Matkowski, A., Jamiołkowska-Kozlowska, W., and Nawrot, I. (2013). Chinese Medicinal Herbs as Source of Antioxidant Compounds-Wwhere Tradition Meets the Future. Curr. Med. Chem. 20, 984-1004. doi:10.2174/ 092986713805288888

Mc Namara, K., Alzubaidi, H., and Jackson, J. K. (2019). Cardiovascular Disease as a Leading Cause of Death: How Are Pharmacists Getting Involved? Integr. Pharm. Res. Pract. 8, 1-11. doi:10.2147/IPRP.S133088

McKnight, S. L., Iglewski, B. H., and Pesci, E. C. (2000). The Pseudomonas Quinolone Signal Regulates Rhl Quorum Sensing in Pseudomonas aeruginosa. J. Bacteriol. 182, 2702-2708. doi:10.1128/jb.182.10.2702-2708.2000 
Meyer, J. M. (2000). Pyoverdines: Pigments, Siderophores and Potential Taxonomic Markers of Fluorescent Pseudomonas Species. Arch. Microbiol. 174, 135-142. doi:10.1007/s002030000188

Michalska, M., and Wolf, P. (2015). Pseudomonas Exotoxin A: Optimized by Evolution for Effective Killing. Front. Microbiol. 6, 963. doi:10.3389/ fmicb.2015.00963

Mikkelsen, H., Sivaneson, M., and Filloux, A. (2011). Key Two-Component Regulatory Systems that Control Biofilm Formation in Pseudomonas aeruginosa. Environ. Microbiol. 13, 1666-1681. doi:10.1111/j.14622920.2011.02495.x

Miller, M. B., and Bassler, B. L. (2001). Quorum sensing in Bacteria. Annu. Rev. Microbiol. 55, 165-199. doi:10.1146/annurev.micro.55.1.165

Moradali, M. F., Ghods, S., and Rehm, B. H. (2017). Pseudomonas aeruginosa Lifestyle: A Paradigm for Adaptation, Survival, and Persistence. Front. Cel Infect Microbiol 7, 39. doi:10.3389/fcimb.2017.00039

National Nosocomial Infections Surveillance (2004). National Nosocomial Infections Surveillance (NNIS) System Report, Data Summary from January 1992 through June 2004, Issued October 2004. Am. J. Infect. Control. 32, 470-485. doi:10.1016/S0196655304005425

O'Toole, G., Kaplan, H. B., and Kolter, R. (2000). Biofilm Formation as Microbial Development. Аnnu. Rev. Microbiol. 54, 49-79. doi:10.1146/ annurev.micro.54.1.49

Ooi, L. S., Li, Y., Kam, S. L., Wang, H., Wong, E. Y., and Ooi, V. E. (2006). Antimicrobial Activities of Cinnamon Oil and Cinnamaldehyde from the Chinese Medicinal Herb Cinnamomum cassia Blume. Am. J. Chin. Med. 34, 511-522. doi:10.1142/S0192415X06004041

Ouyang, M. A., He, Z. D., and Wu, C. L. (2003). Anti-Oxidative Activity of Glycosides from Ligustrum Sinense. Nat. Prod. Res. 17, 381-387. doi:10.1080/ 1057563031000075476

Pang, Z., Raudonis, R., Glick, B. R., Lin, T. J., and Cheng, Z. (2019). Antibiotic Resistance in Pseudomonas aeruginosa: Mechanisms and Alternative Therapeutic Strategies. Biotechnol. Adv. 37, 177-192. doi:10.1016/ j.biotechadv.2018.11.013

Pearson, J. P., Pesci, E. C., and Iglewski, B. H. (1997). Roles of Pseudomonas aeruginosa Las and Rhl Quorum-sensing Systems in Control of Elastase and Rhamnolipid Biosynthesis Genes. J. Bacteriol. 179, 5756-5767. doi:10.1128/ jb.179.18.5756-5767.1997

Rada, B., and Leto, T. L. (2013). Pyocyanin Effects on Respiratory Epithelium: Relevance in Pseudomonas aeruginosa Airway Infections. Trends Microbiol. 21, 73-81. doi:10.1016/j.tim.2012.10.004

Rasamiravaka, T., Labtani, Q., Duez, P., and El Jaziri, M. (2015). The Formation of Biofilms by Pseudomonas aeruginosa: a Review of the Natural and Synthetic Compounds Interfering with Control Mechanisms. Biomed. Res. Int. 2015, 759348. doi:10.1155/2015/759348

Ren, J.-l., Zhang, A.-H., and Wang, X.-J. (2020). Traditional Chinese Medicine for COVID-19 Treatment. Pharmacol. Res. 155, 104743. doi:10.1016/ j.phrs.2020.104743

Richards, M. J., Edwards, J. R., Culver, D. H., and Gaynes, R. P. (1999). Nosocomial Infections in Medical Intensive Care Units in the United States. National Nosocomial Infections Surveillance System. Crit. Care Med. 27, 887-892. doi:10.1097/00003246-199905000-00020

Rutherford, S. T., and Bassler, B. L. (2012). Bacterial Quorum Sensing: its Role in Virulence and Possibilities for its Control. Cold Spring Harb Perspect. Med. 2, a012427. doi:10.1101/cshperspect.a012427

Sadikot, R. T., Blackwell, T. S., Christman, J. W., and Prince, A. S. (2005). Pathogen-host Interactions in Pseudomonas aeruginosa Pneumonia. Am. J. Respir. Crit. Care Med. 171, 1209-1223. doi:10.1164/rccm.200408-1044SO

Samappito, S., Srichaikul, B., Viroj, J., and Bakker, G. (2012). Comparative Study of Double Blind Clinical Trial in Side-Effects Among Areca Catechu 1., Thai Traditional Herbal Formula and Mebendazole. Trop. Parasitol. 2, 116-118. doi:10.4103/2229-5070.105176

Sanz-García, F., Hernando-Amado, S., and Martínez, J. L. (2018). Mutational Evolution of Pseudomonas aeruginosa Resistance to Ribosome-Targeting Antibiotics. Front. Genet. 9, 451. doi:10.3389/fgene.2018.00451

Serra, R., Grande, R., Butrico, L., Rossi, A., Settimio, U. F., Caroleo, B., et al. (2015). Chronic Wound Infections: the Role of Pseudomonas aeruginosa and Staphylococcus aureus. Expert Rev. Anti Infect. Ther. 13, 605-613. doi:10.1586/14787210.2015.1023291
Shan, W., Wang, Y., Zhang, Z., Xing, J., Xu, J., Xiao, W., et al. (2019). Qingre Baidu Mixture-Induced Effect of AI-2 on Staphylococcus aureus and Pseudomonas aeruginosa Biofilms in Chronic and Refractory Wounds. Exp. Ther. Med. 17, 3343-3350. doi:10.3892/etm.2019.7391

Sharifi-Rad, M., Varoni, E. M., Salehi, B., Sharifi-Rad, J., Matthews, K. R., Ayatollahi, S. A., et al. (2017). Plants of the Genus Zingiber as a Source of Bioactive Phytochemicals: From Tradition to Pharmacy. Molecules 22, 2145. doi:10.3390/molecules 22122145

Shingnaisui, K., Dey, T., Manna, P., and Kalita, J. (2018). Therapeutic Potentials of Houttuynia Cordata Thunb. Against Inflammation and Oxidative Stress: A Review. J. Ethnopharmacol 220, 35-43. doi:10.1016/j.jep.2018.03.038

Smith, A. M., Rahman, F. Z., Hayee, B., Graham, S. J., Marks, D. J., Sewell, G. W., et al. (2009). Disordered Macrophage Cytokine Secretion Underlies Impaired Acute Inflammation and Bacterial Clearance in Crohn's Disease. J. Exp. Med. 206, 1883-1897. doi:10.1084/jem.20091233

Stewart, P. S. (2002). Mechanisms of Antibiotic Resistance in Bacterial Biofilms. Int. J. Med. Microbiol. 292, 107-113. doi:10.1078/1438-4221-00196

Sun, J., Deng, Z., and Yan, A. (2014a). Bacterial Multidrug Efflux Pumps: Mechanisms, Physiology and Pharmacological Exploitations. Biochem. Biophys. Res. Commun. 453, 254-267. doi:10.1016/j.bbrc.2014.05.090

Sun, W., Qu, D., Ma, Y., Chen, Y., Liu, C., and Zhou, J. (2014b). Enhanced Stability and Antibacterial Efficacy of a Traditional Chinese Medicine-Mediated Silver Nanoparticle Delivery System. Int. J. Nanomedicine 9, 5491-5502. doi:10.2147/ IJN.S71670

Tacconelli, E., Carrara, E., Savoldi, A., Harbarth, S., Mendelson, M., Monnet, D. L., et al. (2018). Discovery, Research, and Development of New Antibiotics: the WHO Priority List of Antibiotic-Resistant Bacteria and Tuberculosis. Lancet Infect. Dis. 18, 318-327. doi:10.1016/S1473-3099(17)30753-3

Tan Lim, A. M., Oyong, G. G., Tan, M. C. S., Chang Shen, C., Ragasa, C. Y., and Cabrera, E. C. (2021). Quorum quenching Activity of Andrographis Paniculata (Burm f.) Nees Andrographolide Compounds on Metallo- $\beta$-LactamaseProducing Clinical Isolates of Pseudomonas aeruginosa PA22 and PA247 and Their Effect on lasR Gene Expression. Heliyon 7, e07002. doi:10.1016/ j.heliyon.2021.e07002

Tang, J. L., Liu, B. Y., and Ma, K. W. (2008). Traditional Chinese Medicine. Lancet 372, 1938-1940. doi:10.1016/S0140-6736(08)61354-9

Terzi, H. A., Kulah, C., and Ciftci, I. H. (2014). The Effects of Active Efflux Pumps on Antibiotic Resistance in Pseudomonas aeruginosa. World J. Microbiol. Biotechnol. 30, 2681-2687. doi:10.1007/s11274-014-1692-2

Tian, J., Jin, D., Bao, Q., Zhang, H., Gao, Z., Song, J., et al. (2019). Evidence and Potential Mechanisms of Traditional Chinese Medicine for the Treatment of Type 2 Diabetes: A Systematic Review and Meta-Analysis. Diabetes Obes. Metab. 21, 1801-1816. doi:10.1111/dom.13760

Tian, M., Liu, T., Wu, X., Hong, Y., Liu, X., Lin, B., et al. (2020). Chemical Composition, Antioxidant, Antimicrobial and Anticancer Activities of the Essential Oil from the Rhizomes of Zingiber Striolatum Diels. Nat. Prod. Res. 34, 2621-2625. doi:10.1080/14786419.2018.1544979

$\mathrm{Tu}$, Y. (2016). Artemisinin-A Gift from Traditional Chinese Medicine to the World (Nobel Lecture). Angew. Chem. Int. Ed. Engl. 55, 10210-10226. doi:10.1002/ anie. 201601967

Wade, D. S., Calfee, M. W., Rocha, E. R., Ling, E. A., Engstrom, E., Coleman, J. P., et al. (2005). Regulation of Pseudomonas Quinolone Signal Synthesis in Pseudomonas aeruginosa. J. Bacteriol. 187, 4372-4380. doi:10.1128/ JB.187.13.4372-4380.2005

Wang, D., Xie, K., Zou, D., Meng, M., and Xie, M. (2018). Inhibitory Effects of Silybin on the Efflux Pump of Methicillin-resistant Staphylococcus aureus. Mol. Med. Rep. 18, 827-833. doi:10.3892/mmr.2018.9021

Wang, J., Jiao, H., Meng, J., Qiao, M., Du, H., He, M., et al. (2019a). Baicalin Inhibits Biofilm Formation and the Quorum-Sensing System by Regulating the MrrA Drug Efflux Pump in Staphylococcus Saprophyticus. Front. Microbiol. 10, 2800. doi:10.3389/fmicb.2019.02800

Wang, L., Cheng, L., Yuan, Q., Cui, X., Shang, H., Zhang, B., et al. (2010). Adverse Drug Reactions of Shuanghuanglian Injection: a Systematic Review of Public Literatures. J. Evid. Based Med. 3, 18-26. doi:10.1111/j.1756-5391.2010.01067.x Wang, T., Guo, R., Zhou, G., Zhou, X., Kou, Z., Sui, F., et al. (2016). Traditional Uses, Botany, Phytochemistry, Pharmacology and Toxicology of Panax Notoginseng (Burk.) F.H. Chen: A Review. J. Ethnopharmacol 188, 234-258. doi:10.1016/j.jep.2016.05.005 
Wang, T., Huang, W., Duan, Q., Wang, J., Cheng, H., Shao, J., et al. (2019b). Sodium Houttuyfonate In Vitro Inhibits Biofilm Dispersion and Expression of bdlA in Pseudomonas aeruginosa. Mol. Biol. Rep. 46, 471-477. doi:10.1007/ s11033-018-4497-9

Waters, C. M., and Bassler, B. L. (2005). Quorum sensing: Cell-To-Cell Communication in Bacteria. Annu. Rev. Cel Dev Biol 21, 319-346. doi:10.1146/annurev.cellbio.21.012704.131001

Wei, Q., Bhasme, P., Wang, Z., Wang, L., Wang, S., Zeng, Y., et al. (2020). Chinese Medicinal Herb Extract Inhibits PQS-Mediated Quorum Sensing System in Pseudomonas aeruginosa. J. Ethnopharmacol 248, 112272. doi:10.1016/ j.jep.2019.112272

Whiteley, M., Lee, K. M., and Greenberg, E. P. (1999). Identification of Genes Controlled by Quorum Sensing in Pseudomonas aeruginosa. Proc. Natl. Acad. Sci. U S A. 96, 13904-13909. doi:10.1073/pnas.96.24.13904

Winzer, K., Falconer, C., Garber, N. C., Diggle, S. P., Camara, M., and Williams, P. (2000). The Pseudomonas aeruginosa Lectins PA-IL and PA-IIL Are Controlled by Quorum Sensing and by RpoS. J. Bacteriol. 182, 6401-6411. doi:10.1128/ jb.182.22.6401-6411.2000

Wretlind, B., and Pavlovskis, O. R. (1983). Pseudomonas aeruginosa Elastase and its Role in pseudomonas Infections. Rev. Infect. Dis. 5 (Suppl. 5), S998-S1004. doi:10.1093/clinids/5.supplement_5.s998

Wu, D., Huang, W., Duan, Q., and Cheng, H. (2016). Effect of Sodium Houttuyfonate on Symptom Pattern of Lung-Qi Deficiency in Rats Induced by Bacterialbiofilm Infection. J. Tradit Chin. Med. 36, 730-736. doi:10.1016/ s0254-6272(17)30007-9

Wu, D., Huang, W., Duan, Q., Li, F., and Cheng, H. (2014). Sodium Houttuyfonate Affects Production of N-Acyl Homoserine Lactone and Quorum SensingRegulated Genes Expression in Pseudomonas aeruginosa. Front. Microbiol. 5, 635. doi:10.3389/fmicb.2014.00635

Wu, R., Wang, L., Kuo, H. D., Shannar, A., Peter, R., Chou, P. J., et al. (2020). An Update on Current Therapeutic Drugs Treating COVID-19. Curr. Pharmacol. Rep. 6, 1-15. doi:10.1007/s40495-020-00216-7

Xia, R. Y., Hu, X. Y., Fei, Y. T., Willcox, M., Wen, L. Z., Yu, M. K., et al. (2020). Shufeng Jiedu Capsules for Treating Acute Exacerbations of Chronic Obstructive Pulmonary Disease: a Systematic Review and Meta-Analysis. BMC Complement. Med. Ther. 20, 151. doi:10.1186/s12906-020-02924-5

Xiang, Y., Guo, Z., Zhu, P., Chen, J., and Huang, Y. (2019). Traditional Chinese Medicine as a Cancer Treatment: Modern Perspectives of Ancient but Advanced Science. Cancer Med. 8, 1958-1975. doi:10.1002/cam4.2108

Xu, H., Li, M., Wang, C., Yin, R., Ma, J., Wang, M., et al. (2018). Evaluation on Clinical Efficacy of Fuzheng Jiedu Huayu Decoction Combined with Antibiotics in the Treatment of Pneumonia in the Elderly - A multi-center, Double-Blind, Parallel, Randomized Controlled Trial. Complement. Ther. Med. 37, 127-132. doi:10.1016/j.ctim.2017.11.012

Xu, H., Liu, C., Li, M., Wang, C., Liu, G., Wang, H., et al. (2019). In Vitro Antibacterial Experiment of Fuzheng Jiedu Huayu Decoction against Multidrug-Resistant Pseudomonas aeruginosa. Front. Pharmacol. 10, 1682. doi:10.3389/fphar.2019.01682

Xu, Z., Li, K., Pan, T., Liu, J., Li, B., Li, C., et al. (2019). Lonicerin, an Anti-algE Flavonoid against Pseudomonas aeruginosa Virulence Screened from Shuanghuanglian Formula by Molecule Docking Based Strategy. J. Ethnopharmacol 239, 111909. doi:10.1016/j.jep.2019.111909

Yamada, T., Wajima, T., Nakaminami, H., Kobayashi, K., Ikoshi, H., and Noguchi, N. (2016). The Modified Gingyo-San, a Chinese Herbal Medicine, Has Direct Antibacterial Effects against Respiratory Pathogens. BMC Complement. Altern. Med. 16, 463. doi:10.1186/s12906-016-1431-3

Yan, G. L., Zhang, A. H., Sun, H., Han, Y., Shi, H., Zhou, Y., et al. (2013). An Effective Method for Determining the Ingredients of Shuanghuanglian Formula in Blood Samples Using High-Resolution LC-MS Coupled with Background Subtraction and a Multiple Data Processing Approach. J. Sep. Sci. 36, 3191-3199. doi:10.1002/jssc.201300529
Yan, Y., Furumura, M., Gouya, T., Iwanaga, A., Teye, K., Numata, S., et al. (2015) Shikonin Promotes Skin Cell Proliferation and Inhibits Nuclear Factor-Kb Translocation via Proteasome Inhibition In Vitro. Chin. Med. J. (Engl) 128, 2228-2233. doi:10.4103/0366-6999.162512

Yang, D. M., Ouyang, M. A., and Lv, S. Q. (2013). Combined Treatment of Pseudomonas aeruginosa PA01 Biofilm Formation with the Water-Soluble Extract of Ligustrum Sinense and Gentamicin Sulphate. J. Environ. Biol. 34, 451-457.

Yang, W., Wei, Q., Tong, Q., Cui, K., He, G., Lin, L., et al. (2020a). Traditional Chinese Medicine Tanreqing Inhibits Quorum Sensing Systems in Pseudomonas aeruginosa. Front. Microbiol. 11, 517462. doi:10.3389/fmicb.2020.517462

Yang, Y., Islam, M. S., Wang, J., Li, Y., and Chen, X. (2020b). Traditional Chinese Medicine in the Treatment of Patients Infected with 2019-New Coronavirus (SARS-CoV-2): A Review and Perspective. Int. J. Biol. Sci. 16, 1708-1717. doi:10.7150/ijbs.45538

Yu, G. Y., Tian, Z. J., Sun, Y., Yang, H. W., Han, S. J., Miao, R. P., et al. (2017). Review on Advantages and Evidence of Treating and Preventing Urinary Tract Infection in Traditional Chinese Medicine. Zhongguo Zhong Yao Za Zhi 42, 1439-1448. doi:10.19540/j.cnki.cjcmm.2017.0040

Yu, J. S., Ho, C. H., Hsu, Y. C., Wang, J. J., and Hsieh, C. L. (2014). Traditional Chinese Medicine Treatments for Upper Respiratory Tract Infections/common Colds in Taiwan. Eur. J. Integr. Med. 6, 538-544. doi:10.1016/j.eujim.2014.06.003

Zeng, Z., Qian, L., Cao, L., Tan, H., Huang, Y., Xue, X., et al. (2008). Virtual Screening for Novel Quorum Sensing Inhibitors to Eradicate Biofilm Formation of Pseudomonas aeruginosa. Appl. Microbiol. Biotechnol. 79, 119-126. doi:10.1007/s00253-008-1406-5

Zhang, L., Liang, E., Cheng, Y., Mahmood, T., Ge, F., Zhou, K., et al. (2020). Is Combined Medication with Natural Medicine a Promising Therapy for Bacterial Biofilm Infection? Biomed. Pharmacother. 128, 110184. doi:10.1016/j.biopha.2020.110184

Zhang, S. N., Li, X. Z., Tan, L. Y., and Zhu, K. Y. (2021). A Review of Pharmacological and Toxicological Effects of Sophora Tonkinensis with Bioinformatics Prediction. Am. J. Chin. Med. 49, 359-389. doi:10.1142/S0192415X21500178

Zhao, T., Tang, H., Xie, L., Zheng, Y., Ma, Z., Sun, Q., et al. (2019). Scutellaria Baicalensis Georgi. (Lamiaceae): a Review of its Traditional Uses, Botany, Phytochemistry, Pharmacology and Toxicology. J. Pharm. Pharmacol. 71, 1353-1369. doi:10.1111/jphp.13129

Zhao, Z., Miao, Y., Pan, P., Cheng, B., Bai, G., and Wu, H. (2013). Qingfei Xiaoyan Wan Alleviates Asthma through Multi-Target Network Regulation. BMC Complement. Altern. Med. 13, 206. doi:10.1186/1472-6882-13-206

Zulianello, L., Canard, C., Köhler, T., Caille, D., Lacroix, J. S., and Meda, P. (2006). Rhamnolipids Are Virulence Factors that Promote Early Infiltration of Primary Human Airway Epithelia by Pseudomonas aeruginosa. Infect. Immun. 74, 3134-3147. doi:10.1128/IAI.01772-05

Conflict of Interest: The authors declare that the research was conducted in the absence of any commercial or financial relationships that could be construed as a potential conflict of interest.

Publisher's Note: All claims expressed in this article are solely those of the authors and do not necessarily represent those of their affiliated organizations, or those of the publisher, the editors, and the reviewers. Any product that may be evaluated in this article, or claim that may be made by its manufacturer, is not guaranteed or endorsed by the publisher.

Copyright (C) 2021 Pang and Zhu. This is an open-access article distributed under the terms of the Creative Commons Attribution License (CC BY). The use, distribution or reproduction in other forums is permitted, provided the original author(s) and the copyright owner(s) are credited and that the original publication in this journal is cited, in accordance with accepted academic practice. No use, distribution or reproduction is permitted which does not comply with these terms. 